\title{
ACCEPTED ABSTRACTS for the American Academy of Pediatric Neuropsychology (AAPdN) Virtual Conference 2021
}

\author{
Identifying Neurocognitive Late-Effects of a Transgender Patient \\ with Pediatric Leukemia
}

\author{
Nicole Baggett, MS \\ nbaggett@pacificu.edu \\ (949) 302-6666 \\ 730 SE Oak St., Suite F \\ Hillsboro, OR 97123 \\ Pacific University, School of Graduate Psychology \\ Justin B. Lee, PhD \\ justi@ohsu.edu \\ (877) 346-0640 \\ 707 SW Gaines St., Suite 2115 \\ Portland, OR 97239 \\ Oregon Health \& Science University, School of Medicine
}

Objective: Survivors of childhood acute lymphoblastic leukemia (ALL) may demonstrate neurocognitive late effects. There is limited literature regarding neurocognitive functioning of transgender females in light of gender-affirming medical intervention. Moreover, normative samples utilized in neuropsychological tests present a challenge when working with transgender youth. The aim of this case study is to help identify the challenges when working with transgender youth and their families.

Methods: Leia is an 11-year-old transgender female treated with intrathecal chemotherapy for high-risk ALL diagnosed at 2 years. She has not received puberty blockers. Primary concerns with executive functioning and mood were endorsed. Leia was administered a comprehensive neuropsychological battery assessing her cognitive functioning, executive functioning, memory, academic skills, fine motor skills, and emotional and behavioral functioning.

Results: Leia demonstrated strengths in vocabulary, processing speed, and "cold" executive functioning. Conversely, she demonstrated weaknesses in attention, concentration, and "hot" executive functioning skills. The authors debated on the use of gender-specific reference norms for interpreting self- and parent-report questionnaires. When compared to same-aged cisgender girls, Leia's profile was flagged with several more "clinically significant" areas of concern than when compared to sameaged cisgender boys.

Conclusions: Broadly, Leia's performance was commensurate with that of the literature examining neurocognitive late-effects of pediatric ALL. Within that context, these authors considered additional factors that may have moderated Leia's performance including her mood-related concerns, psychosocial difficulties, and the use of gender-specific reference norms. The authors came across limited literature about transgender youth's neuropsychological performance and additional outcomes to consider when working with this population. Of the existing literature, it was apparent that the medical terminology referring to transgender youth was variable and at times outdated and lacking in inclusivity. This clinical case highlighted the growing impetus to address matters of diversity, equity, and inclusion in the field of pediatric neuropsychology.
Sustained Attention's Contribution to Statistical Discrepancy between Reading Comprehension Tasks

Rebecca Bridges, M.A.

rbridges89@midwestern.edu

19555 N 59th Ave, Glendale, AZ 85308

(928)-848-2838

Academic affiliation: Midwestern University, Glendale AZ

Jessica Powell Psy.D.

jpowel2@midwestern.edu

19555 N 59th Ave, Glendale, AZ 85308

(623)-572-3215

Academic affiliation: Midwestern University, Glendale AZ

Objectives: Anecdotally, on the Academic Achievement Battery $(A A B)$, many examinees performed discrepantly on the two reading comprehension tasks that make up the reading comprehension index (e.g., average on Reading Comprehension:Words and Sentences (RC:WS) but borderline on Reading Comprehension:Passages (RC:P)). Higher order functions (like sustained attention) and oral language skills have been thoroughly researched regarding their impact on reading comprehension as a whole; however, there is currently no research examining how these factors may differentially affect varying types of reading comprehension tasks. It was hypothesized that $\left(\mathrm{H}_{1}\right)$ the anecdotally observed poorer performance on $\mathrm{RC}: \mathrm{P}$ compared to RC:WS would be a statistically significant difference, and $\left(\mathrm{H}_{2}\right)$ deficits in sustained attention and oral language would account for a significant amount of variance in examinee's $\mathrm{RC}: \mathrm{P}$ scores.

Methods: Archival data from 43 examinees (16+ years) was collected, which included scores from both reading comprehension tasks on the $A A B$; the Test of Variables of Attention (TOVA) Omission Error Score; and the Wechsler Adult Intelligence Scale, Fourth Edition (WAIS-IV) Vocabulary score.

Results: Results of the two-tailed paired samples $t$ test indicated a significant difference between RC:WS $(M=98.33, \mathrm{SD}=10.48)$ and $\mathrm{RC}: \mathrm{P}(M=90.16, \mathrm{SD} 14.24), t(42)=4.09, p<.001$. A standard multiple regression was conducted to determine the accuracy of the independent variables (RC:WS; TOVA; WAIS-IV Vocab) predicting RC:P scores. Regression results indicate that the overall model significantly predicted RC:P scores $\left[R^{2}=.342, R^{2}{ }_{\text {adj }}=\right.$ $.292, F(3,96)=6.767, p<.001]$ and accounts for $29.2 \%$ of the variance. Beta weights indicate that only two variables, RC:WS $\beta=.471, t(96)=3.50, p=.001$, and TOVA $\beta=.273, t(96)=2.07$, $p=.045$, significantly contributed to the model.

Conclusions: Results indicate that deficits in sustained attention predict a significant amount of variance in RC:P scores, whereas oral language does not. Implications for pediatric and adult neuropsychological evaluations utilizing measures such as the $\mathrm{AAB}$, and intervention implications, are further discussed. 
Authors: Kimberly D. Brown, M.A. (kdbaysbrown@bsu.edu)

Andrew S. Davis, Ph.D. (davis@bsu.edu)

Address: 2000 W. University Ave., North Quad 130, Muncie IN 47306

Office Phone: 765-285-8591

Office Fax: 765-285-1702

Affiliation: Ball State University

\section{Social Relationships and Theory of Mind in Children with ADHD}

\section{Objectives}

The majority of ADHD diagnoses are made in the early elementary years between ages six and eleven. Co-currently, these years are also the time period during which a child is fine tuning their ability to process and infer the thinking and intentions of other people (i.e., theory of mind (ToM). For children with ADHD, distracted attention and inhibition control have a direct impact on a child's ability to navigate social interactions for which ToM is integral. This poster will delineate the empirical evidence available regarding the interaction between ADHD, the development of Theory of Mind, and the impact on the social relationships of the child. Data Selection

Literature was obtained via the following databases: ERIC, Medline, PsychINFO, and PsychARTICLES using publication years of 20002021, peer review, full text availability, English; and the following key terms: ADHD and Theory of Mind. A total of 53 articles were perused; 41 were excluded for inclusion of ASD, Adult Dx of ADHD, FASD, various other Dx, or foreign language. A total of 12 articles remained for evaluation.

The database Web of Science was also used with the search string listed above. A total of 37 articles were perused; 34 were excluded for reasons listed above. A total of 3 articles remained for evaluation. The total number of articles selected and reviewed for relevance are 15 .

Data Analysis

Articles were divided into three areas of content base: theoretical overview of ADHD as it relates to ToM, emphasis on the genetic base of both ADHD and ToM, and, last, emphasis on the environmental aspects of both ADHD and ToM.

Conclusions

The connection of the social challenges of ADHD to ToM is an important association for pediatric neuropsychologists. Understanding the neurological overlap of the executive functioning challenges of ADHD as they relate to the development and use of ToM will increase the pediatric neurologist's ability to provide intervention techniques at strategic times. Implications will be discussed for researchers and practitioners.

Title of proposed presentation: Misrepresentation of Pediatric Acute Neuropsychiatric Syndrome Leads to Misdiagnosis

Presenting/lead author: Taylor S. Bucher

Lead author contact information: Taylor S. Bucher, BA., tbucher@email.fielding.edu, 1114 Vessona Circle, Folsom CA, 95630, 317-519-4387

Co-authors and their email addresses: Sarah Chernoff, M.B.A., schernoff@email.fielding.edu, 205 Hunters Place, Okotoks, AB, CANADA, T1S 1K8, 587-225-7344; Kristine M. Jacquin, Ph.D., kjacquin@fielding.edu, 2020 De La Vina Street, Santa Barbara, CA 93105, 805-898-2949

Affiliation: Fielding Graduate University, 2020 De La Vina Street, Santa Barbara, CA 93105

\section{Theoretical/Commentary: (300)}

Objective: Limited research on the development and longevity of Pediatric Acute Onset Neuropsychiatric Syndrome (PANS) has led to many children being misdiagnosed with Obsessive-Compulsive Disorder (OCD), tic disorders, eating disorders, and Autism Spectrum Disorder (ASD; Pettersson et al., 2019; Robbins et al., 2019). Due to the sudden changes in children, sometimes overnight, many parents question the cause of the changes and are quick to blame vaccinations (Bednarczyk, 2018). Intentions of this commentary are to challenge the assessment and treatment strategies of PANS when it is highly misdiagnosed, and suggest further encouragement in PANS research.

Discussion: Current research implies that PANS is developed from infections, inflammatory reactions, and metabolic disturbances, which will increase in children if not appropriately addressed through proper vaccinations and medications. Increasing evidence between neuropsychiatric disorders and autoimmune diseases lead to questions about the diagnostic criteria, potential triggers, and pathogenic triggers for OCD, ASD, eating disorders, and tic disorders in adolescents (Caroline et al., 2019). Conspiracy theories have caused much turmoil surrounding vaccinations, resulting in higher percentages of unvaccinated children (Bednarczyk, 2018). Lack of awareness, fearmongering, and general ignorance among the public regarding the links between syndromes such as PANS and other disorders can serve to fuel conspiracy theories, including the antivaccination movement (Bednarczyk, 2018).

Conclusion: Increased numbers of unvaccinated children, combined with a cultural fixation on ASD, may add further complexity to the issue of misdiagnosis of PANS. This proposal serves as a call for further research and better education of practitioners surrounding the identification and diagnosis of PANS and related disorders. Similar presentations between PANS and OCD, ASD, eating disorders, and tic disorders create a necessity for pediatric neuropsychologists to educate other professionals and the public about the important role vaccinations play in maintaining children's health and preventing the recurrent infections that may lead to PANS.

\section{References}

Bednarczyk, R. A. (2018). Examining the "why" of vaccine hesitancy. Health Psychology, 37(4), 316-317. https://doi.org/10.1037/hea0000596 Caroline, G., Harris, R. A., Wickström Ronny, AnnaCarin, H., Silverberg-Mörse Maria, Eva, S., \& Mataix-Cols, D. (2019). Establishing a pediatric acute-onset neuropsychiatric syndrome clinic: baseline clinical features of the pediatric acute-onset neuropsychiatric syndrome cohort at Karolinska Institutet. Journal of Child and Adolescent Psychopharmacology, 29(8), 625-633. https://doi.org/10. 1089/cap.2018.0127

Chang, K., Frankovich, J., Cooperstock, M., Cunningham, M. W., Latimer, M. E., Murphy, T. K., . . . Swedo, S. E. (2015). Clinical evaluation of youth with pediatric acute-onset neuropsychiatric syndrome (PANS): recommendations from the 2013 PANS consensus conference. Journal of Child and Adolescent Psychopharmacology, 25(1), 3-13. https://doi.org/10.1089/cap.2014.0084

Pettersson, E., Lichtenstein, P., Larsson, H., Song, J., Attention Deficit/ Hyperactivity Disorder Working Group of the iPSYCH-Broad-PGC Consortium, Autism Spectrum Disorder Working Group of the iPSYCH-Broad-PGC Consortium, Bipolar Disorder Working Group of the PGC, Eating Disorder Working Group of the PGC, Major Depressive Disorder Working Group of the PGC, Obsessive Compulsive Disorders and Tourette Syndrome Working Group of the PGC, Schizophrenia CLOZUK, Substance Use Disorder Working Group of the PGC, Agrawal, A., Børglum, A. D., Bulik, C. M., Daly, M. J., Davis, L. K., Demontis, D., Edenberg, H. J. . . . Polderman, T. J. C. (2019). Genetic influences on eight psychiatric disorders based on family data of 4408 646 full and half-siblings, and genetic data of 333748 cases and controls. Psychological Medicine, 49, 1166-1173. https://doi.org/10.1017/ S0033291718002039

Robbins, T. W., Vaghi, M. M., \& Banca, P. (2019). Obsessivecompulsive disorder: puzzles and prospects. Neuron, 102(1), 27-47. https://doi.org/10.1016/j.neuron.2019.01.046

\section{Attestation:}

By submitting this proposal, I commit to the following: o knowing the relevant background research 
o attending meeting(s) with Dr. Jacquin to analyze data o writing at least one section of the proposal (introduction or discussion) and ensuring all sections are written

o ensuring the conference proposal is well-written and conforms to requirements for proposals for that particular conference

o completing all edits on the proposal to get it ready for submission

o submitting the proposal and all revisions to Dr. Jacquin on time (no exceptions/no lateness possible)

o forwarding all correspondence about the proposal to Dr. Jacquin o ensuring the presentation is prepared, consistent with requirements

o knowing the content of the presentation and all relevant background research exceptionally well

o preparing an "elevator speech" that summarizes the presentation in 1-2 minutes

o practicing the poster in the lab

o printing the poster and bringing it to the conference

$o$ attending the conference and presenting the research at the conference

$o$ attending the presentations of other lab researchers

o staying for the entire conference

I attest and commit to the above.

Taylor S. Bucher

Authors: Adrianna M. Caballero, M.A. (amcaballero@bsu.edu)

April M. Taylor, M.A. (ammullen@bsu.edu)

Address: 2000 W. University Ave., Teachers College 505, Muncie, IN 47306

Office Phone: 765-285-8500

Office Fax: 765-285-3653

Affiliation: Ball State University

\section{Pediatric Neuropsychology: Cross-Cultural Considerations}

\section{Objectives}

Within the field of neuropsychology, the majority of neuropsychological assessments have been developed and normed using a Western/European context (Fernandez \& Evans, 2018). Using Western/European context as a basis for neuropsychological assessment is substandard when assessing patients from different culturally and linguistically diverse (CLD) backgrounds. The Relevance 2050 Initiative (AACN, 2020) predicts by the year 2050, a full $60 \%$ of the American population will be "untestable" based on the majority of the field's mono-lingual, mono-cultural assessments. While cross-cultural considerations for neuropsychological practice have been explored, the cross-cultural implications for pediatric neuropsychology remain scarce. Cross-cultural neuropsychological assessment practices for pediatric patients historically have been a downward extension from adult neuropsychological practice (Marlowe, 2000). This practice is substandard as it fails to address the unique and known differences in the functional organization of the brain and cognitions of CLD pediatric patients. The purpose of this review is to examine the crosscultural considerations within the field of pediatric neuropsychology in order to better understand cultural factors that influence pediatric performance on neuropsychological tests while promoting psychometrically accurate assessments.

\section{Data Selection}

Literature was obtained via searches of peer-reviewed journals available in the following databases: Academic Search Premier, PsycInfo, PsycArticles, ERIC, and PubMed using combinations of the following search terms: "pediatric," cross-cultural," and "neuropsychological assessment." Journals were included if they were scholarly and peerreviewed. A total of 11 articles were found with 8 articles being retained for relevancy.

Data Analysis

All 8 articles obtained were reviewed and synthesized.

Conclusions

Despite the research and considerations for conducting a valid crosscultural neuropsychological assessment for culturally and diverse adults, the research and implications for cross-cultural assessment for CLD children is limited. This review will provide a synthesis of available literature on the implications of cross-cultural neuropsychological assessment for children and explore future directions.

\section{Amantadine Induced Livedo Reticularis in a Rubinstein-Taybi Type} II Patient

Cody Capps, B.S. ccapps3210@gmail.com

Darlyne G. Nemeth, Ph.D., M.P., M.P.A.P.

dgnemeth@gmail.com

The Neuropsychology Center of Louisiana, LLC., (NCLA)

\section{Abstract}

Amantadine is often used for hyperactivity and irritability in patients with Autism and Attention-Deficit/Hyperactivity Disorder (ADHD). Typically, Amantadine can be prescribed at $100 \mathrm{mg}$ BID; however, patients with Rubinstein-Taybi Type II (RTTII) can experience a side effect, Livedo Reticularis. RTTII has an autosomal pattern of inheritance that occurs in 1/1000 newborns. When prescribing Amantadine to an RTTII young adult, it is recommended that the starting dose be somewhat lower than suggested. The liquid dose, $50 \mathrm{mg} / 5 \mathrm{ml}$, of Amantadine can be effective in reducing any potential Livedo Reticularis, which was seen as bulging blood vessels. Since this individual's hyperactivity and irritability were controlled by Amantadine 100mg BID, a medication reduction to a more tolerable level was utilized with positive results. With the assistance of ongoing individual and family therapy, as well as medication management, this young man was able to complete high school and was able to attend a residential college for special needs adults. Therefore, discontinuation of an effective medication may not always be the answer. This poster aims to configure etiology and inform prescribers how to establish patients with RTTII on Amantadine.

\section{References:}

Quaresma MV;Gomes AC;Serruya A;Vendramini DL;Braga L;Buçard AM;. (2015). Amantadine-induced livedo reticularis-case report. Retrieved January 17, 2021, from https://pubmed.ncbi.nlm.nih.gov/ 26560223/

Cody M. Capps, B.S.

ccapps3210@gmail.com

Olesia Palamar

olesapalamar@gmail.com

Fernando Pastrana, Ph.D.

nclag310@gmail.com

Darlyne G. Nemeth, Ph.D., M.P.

dgnemeth@gmail.com

The Neuropsychology Clinic of Louisiana, LLC.

4611 Bluebonnet Blvd. Suite B

Baton Rouge, LA 70809

Phone: (225)926-7500 Fax: (225)924-0188

\section{The Effect of OCD and ADD on Intellectual Functioning}

\section{Objective:}

Obsessive-compulsive disorder (OCD) causes repetitive unwanted thoughts or sensations (obsessions) and/or the urge to do something over and over again (compulsions). Attention-Deficit/Hyperactivity Disorder (ADHD) often involves inattention, hyperactivity, and impulsivity. Children with untreated OCD and ADHD may experience difficulties optimizing their true intellectual abilities. A comprehensive evaluation and treatment program is most effective in maximizing these children's overall functioning. This tween was prescribed cognitive behavior therapy and medication. His therapy included both individual and family sessions, and his medication included Aptensio XR and Guanfacine HCL 
ER. As a result of the aforementioned interventions, this tween was able to utilize his full intellectual potential, which allowed him to qualify for gifted. In this case, indicators from the WISC-V helped to identify his progress in treatment off and on medications. With the reduction in his OCD thinking, this tween was able to experience improved working memory and processing speed. Both of these two skills had been negatively impacted by his untreated OCD and ADHD.

\section{References:}

Bhandari, S. (2020, September 04). OCD: types, symptoms, causes, diagnosis, treatment, and related conditions. Retrieved January 24, 2021, from https://www.webmd.com/mental-health/obsessive-compulsivedisorder

Nemeth, D. G., \& Glozman, Z. M. (2020). Evaluation and treatment of neuropsychologically compromised children. London, San Diego, CA, CA: Academic Press

Authors: Brian Cheline, M. A. (bccheline@bsu.edu)

Eric. E. Pierson, Ph.D. (eepierson@bsu.edu)

Andrew S. Davis, Ph.D. (davis@bsu.edu)

Address: 2000 W. University Ave., Teachers College 505, Muncie, IN 47306

Office Phone: 765-285-8500

Office Fax: 765-285-3653

Affiliation: Ball State University

\section{Academic Effects of Pediatric Medulloblastoma: Implications for} Effective School-Based Intervention

\section{Objectives}

Medulloblastoma is the most common malignant CNS tumor of pediatric patients. Patients diagnosed with and treated for medulloblastomas often experience neurocognitive decline which can result in areas of academic deficits such as, reading, writing, and math. These difficulties may be further exacerbated by psychiatric concerns. The purpose of this poster is to review the current literature on academic implications of pediatric medulloblastoma and make recommendations for school-based interventions aimed at remediation of academic deficits.

\section{Data Selection}

A literature was conducted using the following databases: PsycINFO, PsycARTICLES, ERIC, MEDLINE, and PubMed using combinations of the following search terms: 'Medulloblastoma' AND 'Academic' OR 'Academic Achievement' OR 'Academic Performance' OR 'Academic Success' OR 'Academic Intervention' AND 'Children' OR 'Adolescent' OR 'Youth' OR 'Child' AND 'Reading' OR 'Math' OR 'Writing'. A total of 18 peer reviewed articles were found with 15 being relevant to pediatric neuropsychology.

\section{Data Analysis}

Fifteen articles were reviewed and synthesized. A variety of journals published articles on Pediatric Medulloblastoma. Only two were published in journals relating to neuropsychology.

\section{Conclusion}

Currently, little research exists on academic intervention implementation for patients experiencing late effects that occur due to pediatric medulloblastomas. The presence of late effects often varies and appear within a few months post-treatment. Longitudinal studies examining late effects have indicated steady declines in academic achievement scores through yearly testing following treatment with slight variation between patient scores due to various factors such as age of treatment, and treatment type and intensity. To help prevent these late effects, research has identified intervention implementation during treatment as a potential protective factor. However, due to patient variability of late effect deficits resulting from pediatric medulloblastomas and treatment, research has identified a current need to further investigate effective approaches to academic intervention implementation both during and after treatment.
AAPdN Conference Proposal

Theoretical/Commentary Abstract

Year of Conference: 2021

Title: Severe Early Childhood Neglect Leads to Smaller Adult Brain Size Presenting author: Sarah Chernoff, M.B.A., 205 Hunters Place, Okotoks, AB, CANADA, T1S 1K8, 587-225-7344, schernoff@email.fielding.edu

Co-author: Kristine M. Jacquin, Ph.D., 2020 De La Vina Street, Santa Barbara, CA, 93105, 805-898-2949, kjacquin@ fielding.edu

Affiliation: Fielding Graduate University, 2020 De La Vina Street, Santa Barbara, CA, 93105, 805-898-2949

Summary:

Objectives: Severe neglect, maternal deprivation, and other forms of extreme adversity in the first few years of life have been linked to neurobiological changes, including changes in brain structure and volume (Gerin et al., 2019; Mackes et al., 2020; Teicher \& Samson, 2016; van Bodegom et al., 2017). Until recently, most research on the relationship between severe early childhood deprivation and neglect and alterations within the brain has been conducted on animals (Hodel et al., 2015; Mackes et al., 2020). This proposed presentation intends to highlight the devastating consequences of deprivation and neglect that last through adulthood, as well as to call attention to the continued international practice of institutionalization of infants and toddlers.

Discussion: Recent studies have shown that humans who experienced significant neglect and/or deprivation through placement in institutions such as orphanages in the first few years of life suffer from neuropsychological consequences in adulthood, including decreased brain volume (Gerin et al., 2019; Hodel et al., 2015; Mackes et al., 2020). Furthermore, these neurological changes are more significant when the neglect or deprivation occurs during early childhood and are not reduced by subsequent nurturing or attachment (Hodel et al., 2015; Mackes et al., 2020; Teicher et al., 2016; van Bodegom et al., 2017). These neurobiological outcomes are directly linked to mental health problems (Gerin et al., 2019; Mackes et al., 2020; Teicher et al., 2016).

Conclusion: Parents in many Western countries choose to adopt children who may have been institutionalized in developing countries. It is vital that pediatric neuropsychologists who may assess such children understand the myriad potential outcomes stemming from deprivation and/or neglect in orphanages and similar institutions, and that these outcomes may not be preventable through adoption into a caring home. Government aid organizations should provide support towards development of systemic alternatives for children requiring care.

\section{References:}

Gerin, M. I., Hanson, E., Viding, E., \& McCrory, E. J. (2019). A review of childhood maltreatment, latent vulnerability and the brain: implications for clinical practice and prevention. Adoption \& Fostering, 43(3), 310328. https://doi.org/10.1177/0308575919865356

Hodel, A. S., Hunt, R. H., Cowell, R. A., Van Den Heuvel, S. E., Gunnar, M. R., \& Thomas, K. M. (2015). Duration of early adversity and structural brain development in post-institutionalized adolescents. NeuroImage, 105, 112-119. https://doi.org/10.1016/j.neuroimage.2014.10.020

Mackes, N. K., Golm, D., Sarkar, S., Kumsta, R., Rutter, M., Fairchild, G., Mehta, M. A., \& Sonuga-Barke, E. J. S. (2020). Early childhood deprivation is associated with alterations in adult brain structure despite subsequent environmental enrichment. Proceedings of the National Academy of Sciences, 117(1), 641-649. https://doi.org/10.1073/pnas. 1911264116

Teicher, M. H., \& Samson, J. A. (2016). Annual research review: enduring neurobiological effects of childhood abuse and neglect. (2016). Journal of Child Psychology and Psychiatry, 57(3), 241-266. https:// doi.org/10.1111/jepp.12507

van Bodegom, M., Homberg, J. R., \& Henckens, M. J. A. G. (2017). Modulation of the hypothalamic-pituitary-adrenal axis by early life stress exposure. Frontiers in Cellular Neuroscience, 11(87), 1-33. https://doi. org/10.3389/fncel.2017.00087 
AAPdN Conference Proposal

Year of conference: 2021

Title of proposed presentation: Childhood Nightmares alter Neurological Functioning and may Predict Adult Psychopathology

Presenting/lead author: Kasey Connors-Beron, M.S.

Lead author contact information: 34 Michigan Ave, Pittsfield, MA 01201, 413-441-4479, kconnors-beron@email.fielding.edu

Co-authors and their email addresses:

Kristine M. Jacquin, Ph.D., kjacquin@ fielding.edu

\section{Abstract:}

Nightmares in childhood result in short-term and long-term psychological and neurological consequences. The consistent presence of stress changes responses within the pituitary-adrenal system, resulting in an increased likelihood in developing mental illness in adulthood. However, longitudinal research has not been conducted to determine if childhood nightmares indicate later life psychopathology.

\section{Summary:}

Nightmares are a common occurrence in childhood with prevalence rates ranging from 17 to $80 \%$ reporting at least one nightmare (Gauchat et al., 2014). More concerning is the prevalence of those experiencing frequent nightmares, $40 \%$, which is defined as at least one per week (Levin et al., 2002). While the specific causes of nightmares have yet to be determined, research suggest that early maternal attachment, specifically maternal separation, has an impact (Csóka et al., 2011). The short-term impact of nightmares in children has been well researched, with psychological symptoms being widely reported (Csóka et al., 2011; Kirov \& Brand, 2011; Levin \& Fireman, 2002; McMakin \& Alfano, 2015; Murray, 1991; Nielsen \& Levin, 2007). However, neurological factors have been less wellestablished although may create life-long changes within the brain. For example, increased pituitary-adrenal responses due to early stress can prime the system to stress later in life (Csóka et al., 2011). Additionally, dysfunction in areas of the brain responsible for affect regulation, such as the amygdala and anterior cingulate cortex, result in the occurrence and maintenance of nightmares (Nielsen \& Levin, 2007). The neurological changes imply a lower stress tolerance in adulthood, increasing the likelihood of continued nightmares. This is supported by 2 to $6 \%$ of adults reporting weekly nightmare attacks (Levin \& Fireman, 2001). Frequent nightmares are a sign of psychological disorders. While nightmares are linked to post-traumatic stress disorder (PTSD), they also appear in individuals with anxiety, depression, eating disorders, and personality disorders (Kirov \& Brand, 2011). Longitudinal research is needed to aid in establishing a connection between childhood nightmares and neurological changes that can impact the affect regulation system and subsequently increase the risk for mental illnesses that have a large emotion component.

\section{References:}

Csóka, S., Simor, P., Szabó, G., Kopp, M. S., \& Bódizs, R. (2011). Early maternal separation, nightmares, and bad dreams: results from the Hungarostudy Epidemiological Panel. Attachment \& Human Development, 13(2), 125-140. https://doi.org/10.1080/14616734.2011. 553991

Gauchat, A., Seguin, J. R., \& Zadra, A. (2014). Prevalence and correlates of disturbed dreaming in children. Pathologie Biologie, 62(5), 311-318. https://doi.org/10.1016/j.patbio.2014.05.016

Kirov, R., \& Brand, S. (2011). Nightmares as predictors of psychiatric disorders in adolescence. Current Trend in Neurology. http://edoc.unibas. $\mathrm{ch} / \mathrm{dok} / \mathrm{A} 6004852$

Levin, R., \& Fireman, G. (2002). Nightmare prevalence, nightmare distress, and self-reported psychological disturbance. Sleep, 25(2), 205-212. McMakin, D. L., \& Alfano, C. A. (2015). Sleep and anxiety in late childhood and early adolescence. Current Opinion in Psychiatry, 28(6), 483. https://doi.org/10.1097/YCO.0000000000000204
Murray, J. B. (1991). Psychophysiological aspects of nightmares, night terrors, and sleepwalking. The Journal of General Psychology, 118(2), 113-127.

Nielsen, T., \& Levin, R. (2007). Nightmares: a new neurocognitive model. Sleep Medicine Reviews, 11(4), 295-310. https://doi.org/10.1016/j. smrv.2007.03.004

Broadening Early Intervention Schedules to include Prenatal and Periconceptional Model

Amanda Coon, B.S. \& Terri G.S. Harris, M.S.

Correct Abstract Title:

Broadening Early Intervention Schedules to Include Prenatal and Periconceptional Model

Updated Contact Information for Authors:

First Author: Amanda M. Coon, B.S.

Email: amanda coon2006@hotmail.com

Address: 2348 W Carriage Lane, Peoria, IL 61614

Ph: (309) 221-6738

Affiliation: Capella University

Co-Author: Terri G.S. Harris, M.S.

Email: tgscott10@gmail.com

Address: 9413 N $16^{\text {th }}$ Street, Tampa, FL 33612

Ph: (813) 323-7517

Affiliation: Peer-led Psychology Research Lab of Independent Study

Corrected submission:

Broadening Early Intervention Schedules to Include Prenatal and Periconceptional Model

Amanda M. Coon, B.S.

amanda_coon2006@hotmail.com

27 W Carriage Lane, Peoria, IL 61614

$\mathrm{Ph}:$ (309) 221-6738

Capella University

Terri G.S. Harris, M.S.

tgscott10@gmail.com

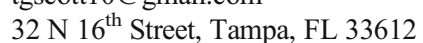

33 323-7517

Peer-led Psychology Research Lab of Independent Study

\section{Objective}

There are numerous factors that go hand-in-hand with the development of healthy human beings. These factors include the use of early, earlier, and the earliest interventions to assist in the best outcomes of children born via natural reproduction methods. Early interventions - a well-established area-generally target postnatal child development from birth to two years of age, whereas earlier interventions refer to prenatal care methods that are implemented from conception through birth. Lastly, the earliest interventions for best child developmental outcomes include periconceptional mediations that encompass the reproductive years until conception. This literature review will discuss the impact of parental (maternal and paternal) life experiences during the periconceptional, prenatal, and postnatal stages of fetal, infant, and child development. Under the gaze of family systems theory, this review will also discuss how the parent-child relationship develops and persists across the lifespan. Physiological, biological, psychosocial, and neurological topics are included in this review as well. The review concludes with an in-depth perspective on prevention, preparation, and interventions for neurodevelopmental diagnoses such as autism spectrum disorder. Data Selection

Using the PsychArticles database, articles for this review were selected using keywords and search terms related to periconceptional, prenatal, and postnatal health of parents and their children. Related theories, interventions, and preventative methods were also searched. Search results returned two hundred articles. Based on inclusionary criteria for this review, eighteen articles were selected for use. 


\section{Conclusion}

Outcomes from this review insinuate the need for closer attention to be made to the connection of overall parental health and child developmental outcomes that persist across the lifespan. Persons attending the poster session of this review will leave with a broader understanding of interventions that are implemented at each stage of child development through periconceptional, prenatal, and postnatal parental care methods.

Note: All data described in this abstract have been collected prior to its submission and in an ethical manner. This abstract has not been previously presented at a regional, national, or international meeting. All coauthors have reviewed the abstract and agreed to be listed as co-authors. Authors:

Charles Cruise, Ph.D., M.A. ${ }^{\text {a }}$

Karina Puent, B.S. ${ }^{\mathrm{b}}$

Lauren Stone, B.S. ${ }^{\text {a }}$

Meghan Cahill, Psy.D. ${ }^{\mathrm{c}}$

Peter Dodzik, Psy.D., ABN, ABPdN ${ }^{\mathrm{c}}$

a: Wheaton CollegeEmail: chuck.cruise@my.wheaton.edu, lauren.stone@my.wheaton.edu Address:12501 College Ave. Wheaton, IL. 60187 Phone: (224) 230-7595Fax: (847) 577-1558

b: Midwestern University

Email: kpuent48@midwestern.edu

Address: $55531^{\text {st }}$ Street, Downers Grove, IL 60515

Phone: (608) 799-0413

Fax: (847) $577-1558$

${ }^{c}$ : Northwest Behavioral Health ServicesEmail: lcampo@nwbhs.comAddress: 415 West Golf Road, Suite 16. Arlington Heights, IL. 60005Phone: (847) 577-0904Fax: (847) 577-1558

\section{Impact of COVID-19 on Cognitive and Emotional Functioning: Case Study}

Objectives: The objective of this study was to determine the pattern and severity of new-onset cognitive and emotional symptoms in a collegeaged female five months post COVID-19 infection.

Case History: This is a 19-year-old, Caucasian female with a history of COVID-19 infection diagnosed in early September 2020. Prior medical history was unremarkable, and she followed a typical course for the condition. She was neither hospitalized nor otherwise treated beyond quarantine and OTC medications for symptom relief. Following her recovery from the illness, she had persistent anosmia as well as reported deficits in cognitive efficiency, working memory, and attention. She reported worsening of previous anxiety and school failure.

Results: Neuropsychological testing completed in mid-January 2021 revealed high average FSIQ with significant discrepancy in cognitive efficiency $(\mathrm{GAI}=117, \mathrm{CPI}=98,10 \% \mathrm{BR})$. She showed depressed scores on measures of academic fluency and mild impairments on subjective and objective measures of working memory and executive functioning. Measures of impulse control and general memory were average. Compared to premorbid psychological testing available from 2017, she showed significant increases in anxiety, panic attacks, and ADHD symptoms. School accommodations, outpatient therapy, and polypharmacy were initiated with good benefit. She returned to college under a different major after receiving failing grades in her previous major in the fall term. Conclusions: Recent studies indicate that around 33\% of individuals (including children and adolescents) demonstrate new-onset cognitive and psychological sequelae following COVID-19 infection, even at 6 months post-recovery. The present case illustrates a pattern and duration of deficits seen in some patients following COVID-19 infection.

Authors: Brittany A. Dale, Ph.D. (badlae@bsu.edu)

Kassandra A. R. Shellabarger, M.A. (kashellabar2@bsu.edu)

Holmes W. Finch, Ph.D. (whfinch@bsu.edu)

Address: 2000 W. University Ave., Teachers College 505, Muncie, IN 47306
Office Phone: $765-285-8500$

Office Fax: 765-285-3653

Affiliation: Ball State University

\section{Performance of Children with ASD on the WISC-V Ancillary Indexes}

\section{Objectives}

Children with autism spectrum disorder (ASD) demonstrate a diverse pattern of performance on the Wechsler Intelligence Scales for Children (WISC) in comparison to their typically developing peers making index interpretation complex. Previous literature has suggested the General Ability Index (GAI) may provide a more accurate estimate of intelligence for children with ASD. Due to the lack of research demonstrating cognitive profiles of children with ASD on the Ancillary Indexes, we sought to explore this population's pattern of performance on the WISC-V Ancillary Indexes using a discriminant analysis to suggest which scale may be the most accurate representation of their true cognitive abilities.

\section{Methods}

The current study utilized the standardization sample data of the WISC-V obtained from NCS Pearson, Inc., which consisted of 62 children diagnosed with ASD, 30 with an accompanying language impairment (Autism-L) and 32 without an accompanying language impairment (Autism-NL), and their demographically matched controls. A discriminant analysis was performed.

\section{Results}

Discriminant analysis identified a significant difference among groups, and demonstrated that the Auditory Working Memory Index (AWMI), Cognitive Proficiency (CPI), and the Full Scale IQ (FSIQ) contributed the most to group differences among the control, Autism-L, and Autism-NL groups. The gaps in means between the control and Autism-NL groups were smaller than the gaps in means between the Autism-NL and AutismL groups.

\section{Conclusions}

The results of this study revealed that AWMI, CPI, and FSIQ were the best at discriminating among the different groups suggesting that the various groups preform differently on these indexes. Furthermore, the GAI displayed one of the lowest discriminant factors, which supports previous literature indicating that the GAI may be a more accurate overall index for children with ASD. It is essential for pediatric neuropsychologists to have an awareness of the usefulness of the ancillary indexes when working with children with ASD.

\section{Maternal Gestational Diabetes Mellitus and Autism Spectrum Disorders in Offspring}

Authors: Breanna E. Ferguson, M.A. (beferguson@bsu.edu)

Andrew S. Davis, Ph.D. (davis@bsu.edu)

Breya L. Whitefield, M.A. (blwhitefield@bsu.edu)

Address: 2000 W. University Ave., Teachers College 705A, Muncie, IN 47306

Office Phone: 765-285-8500

Office Fax: 765-285-3653

Affiliation: Ball State University

\section{Objectives}

The prevalence of Autism Spectrum Disorder (ASD) is increasing and is mirrored by an increase in maternal obesity and Gestational Diabetes Mellitus (GDM). There is a potential association between maternal metabolic conditions (MC) and the risk for ASD in offspring. Some studies have found statistically significant associations between these conditions, whereas others have not. This poster will review the existing literature on maternal MCs as potential environmental factors that, when combined with genetics, may interact to result in ASD in children. There is a need for further investigation into the potential role of glycemic control in early pregnancy as a preventative factor for ASD. 


\section{Data Selection}

Literature was obtained via searches of journals available in the following databases: PsycINFO, PsycARTICLES, ERIC, and MEDLINE with Full Text using combinations of the following search terms: 'Gestational Diabetes' or 'GDM' or 'Gestational Diabetes Mellitus' or 'Diabetes in Pregnancy' and 'Autism' or 'ASD' or 'Autism Spectrum Disorder' or 'Autism Spectrum Disorders'. The search was limited to peer-reviewed articles founded in academic journals. A total of 68 articles were found and 10 articles were retained based on exclusionary criteria. Exclusionary criteria included reviews, metanalyses, and literature that is not peerreviewed and found in academic journals.

Data Analysis

The 10 relevant articles were reviewed and synthesized using their findings on the potential relationship between Maternal MC and ASD. Most were from medical, pediatric, and Autism-related journals.

\section{Conclusions}

A review of the literature noted multiple significant associations between maternal GDM and risk for ASD in offspring. These conclusions are tempered as other studies found no significant association between GDM and ASD but did find associations between ASD and other maternal factors. This poster will review these findings and discuss the implications for pediatric neuropsychologists.

\section{Co-occurrence of Intellectual Disabilltiy and Autism Spectrum Disorder: Neuropsychological Profile}

Steven P. Greco, PhD, ABN, sgreco@nrslifespan.com, 2100 Route 33, Suite 9-10, Neptune, NJ 07753, 732-988-3441, Fax: 732-988-7123, [1,2] Joseph P. Renninger, PsyD, joseph.renninger@gmail.com, 2100 Route 33, Suite 9-10, Neptune, NJ 07753, 732-988-3441, Fax: 732-988-7123, [2] Shannon M. Kirk, smkirk@muhlenberg.edu, 2100 Route 33, Suite 9-10, Neptune, NJ 07753, 732-988-3441, Fax: 732-988-7123, [2]

Alison A. Risko, alisonrisko@gmail.com, 2100 Route 33, Suite 9-10, Neptune, NJ 07753, 732-988-3441, Fax: 732-988-7123, [2] Michael J. Raymond, PhD, ABN, mraymondphd@gmail.com, 2100 Route 33, Suite 9-10, Neptune, NJ 07753, 732-988-3441, Fax: 732-988-7123, [2]

[1] Department of Psychiatry, Jersey Shore University Medical Center

[2] Neuropsychology Rehabilitation Services|Lifespan Behavioral Health, Neptune, NJ

Objectives: To determine the presence of Autism Spectrum Disorder in an adolescent with Mild Intellectual Disability. Describe the neuropsychological profile of an adolescent who meets the criteria for both Intellectual Disability (ID) and Autism Spectrum Disorder (ASD).

Methods: The patient is a 15-year-old female with global developmental delays. She was diagnosed with failure to thrive, speech articulation difficulties, mild intellectual disability, right sensorineural hearing loss, and tonic-clonic seizures with left-frontal and occipital region foci. Medications included Ativan, Zoloft, Risperidone, and birth control. Patient experienced fluctuating moods with transient behavioral dyscontrol. Patient completed consultation and assessment including the following measures: Checklist for Autism Spectrum Disorder (CASD), Behavior Assessment System for Children- $3^{\text {rd }}$ Edition (BASC-3, parent report), Adaptive Behavior Assessment System $-3^{\text {rd }}$ Edition (ABAS3), and Autism Diagnostic Observation Schedule-Second Edition (ADOS-2).

Results: Social/developmental profile revealed concerns regarding hyperactivity, aggression, anxiety, somatic behaviors, inattention, withdrawal, atypicality, adaptability, social skills, leadership, and completing activities of daily living. All areas of adaptive functioning fell within the severely impaired range. The CASD was remarkable for sensory, atypical communication, social interaction, perseveration, atypical development, and mood disturbance. Finally, ADOS-2 assessment fell within the Autism range. Pattern analysis yielded consistent results.
Conclusion: This adolescent was diagnosed with ID with co-occurring ASD. An overlap between genotype and phenotype exists between ASD and ID. One distinction is that the social/communication deficits are more pronounced within the ASD population. Common features of ASD include relatively lower verbal skills than ID; however, research suggests a possible overlap of up to $70 \%$. At all levels of ID, social/communication deficits and repetitive or restrictive behaviors in ASD result in more functional impairment and lower adaptive skills than ID alone. Consideration regarding relative levels of deficits observed and measured is advised. Lastly, diagnosis of ID without ASD is more common when verbal skills are commensurate with nonverbal abilities.

\section{Neonatal Abstinence Syndrome (NAS): a Neuropsychological Case Study}

Steven P. Greco, PhD, ABN, drstevengreco@icloud.com, 2100 Route 33, Suite 9-10, Neptune, NJ 07753, 732-988-3441, Fax: 732-988-7123, $[1,2]$

Joseph P. Renninger, PsyD, joseph.renninger@gmail.com, 2100 Route 33, Suite 9-10, Neptune, NJ 07753, 732-988-3441, Fax: 732-988-7123, [2]

Shannon M. Kirk, smkirk@muhlenberg.edu, 2100 Route 33, Suite 9-10, Neptune, NJ 07753, 732-988-3441, Fax: 732-988-7123, [2]

Joseph P. Haughey, PsyD, josephhaughey3 @ gmail.com, 2100 Route 33, Suite 9-10, Neptune, NJ 07753, 732-988-3441, Fax: 732-988-7123, [2] Michael J. Raymond, PhD, ABN, mraymondphd@gmail.com, 2100 Route 33, Suite 9-10, Neptune, NJ 07753, 732-988-3441, Fax: 732988-7123, [2]

[1] Department of Psychiatry, Jersey Shore University Medical Center [2] Neuropsychology Rehabilitation Services Lifespan Behavioral Health, Neptune, NJ

Objectives: To describe the neuropsychological consequences of Neonatal Abstinence Syndrome (NAS).

Methods: The patient is a 9-year-old male, born premature with positive exposure to opiates. He was hospitalized for $8-10$ weeks in the NICU before he could breathe on his own, but remained on an apnea monitor until 9 months of age. Developmental milestones fell within the normal range. He was also treated for amblyopia. Prior assessment revealed high IQ scores but weak academic skills and was provided with an Individualized Education Program (IEP) which provided academic accommodations, speech/ occupational therapy, and supportive counseling. The patient is currently in the 4 th grade and continues to experience academic difficulties. Neuropsychological assessment included the Meyers Neuropsychological Battery and measures of general intelligence, academic achievement, and personality features.

Results: Testing revealed a pattern of diffuse deficits consistent with NAS and subsequent learning disabilities in reading/dyslexia, written expression, and mathematics. Specific deficits were noted in attention/ concentration and organization. A decline in both intellectual and academic performance was noteworthy when contrasted to a prior assessment. Behavioral observations included difficulty with self-regulation and social functioning.

Conclusion: NAS is a disorder affecting children prenatally exposed to opiates or other substances. NAS is associated with preterm delivery, low birth weight, poor feeding, and excessive crying. Many children with NAS, especially boys, exhibit lower cognitive functioning by age three compared to non-exposed peers. Even those who are indistinguishable from non-exposed peers experience developmental limitations which often persist into early adulthood. Many exhibit a higher rate of emotional/ behavioral, visual, language, motor coordination, and gastrointestinal problems. Early and continuous therapeutic interventions are essential for providing the family with necessary support while enhancing the child's overall level of adaptive functioning. 
AAPdN Conference Proposal

Year of conference: 2021

Title of proposed presentation: Language Development in Children in Multilingual Households

Presenting/lead author: Polina Kats-Kariyanakatte M.S. 1333 School Ln. Rydal, PA 19046 412-656-3453 pkats-kariyanakatte@email.fielding.edu

Co-authors: Janine M. Ray, M.A., jray@email.fielding.edu; Kristine M. Jacquin, Ph.D., kjacquin@ fielding.edu

\section{Summary: \\ Objectives}

Multilingual children are extremely varied with different linguistic combinations and abilities (Unsworth et al., 2014). Socioeconomic factors, family background, and exposure to multiple languages have been shown to impact language development in children (Altikanmis \& Simon, 2020). Bilingual or multilingual acquisition of language occurs in varied contexts, which influence the developmental sequence of languages (Bedore \& Pena, 2008; Thordardottier et al., 2006).

\section{Discussion}

The majority of existing research in the area focused on the development and proficiency of the majority language; however, the development of language is only conceivable when all spoken languages are considered (Altikanmis \& Simon, 2020). Exposure patterns and language input are crucial for the development of language in all children but even more critical in multilingual environments as the patterns of multiple language acquisition are influenced by the amount and type of language data (Almeida et al., 2017; Bohnacker et al., 2016; Duncan \& Paradis, 2018). Linguistic quality and quantity are the two most important characteristics of overall language development (Altikanmis \& Simon, 2020). Not all linguistic input is syntactically complex enough or rich enough lexically to trigger full linguistic development (Altikanmis \& Simon, 2020). The interactions that multilingual children have are not equally divided between languages and children might favor one (or more) languages at home and others outside (Altikanmis \& Simon, 2020).

\section{Conclusion}

Nearly $1 / 4$ of children in the U.S. speak a language other than English at home (Kids Count Data Center, 2018). As the number of children growing up in multilingual households increases, there is a need for further investigation of language development in such children (Altikanmis \& Simon, 2020). Conflicting research findings suggest that multiple language acquisition might be both domain-specific and language-specific (Antonova-Ünlu, 2019). Further research into children with multilingual languages will inform developmental neuropsychology in language acquisition.

\section{References:}

Almeida, L., Ferre, S., Morin, E., Prevost, P., dos Santos, C., Tuller, L., Zebib, R., \& Barthez, M. (2017). Identification of bilingual children with specific language impairment in France. Linguistic Approaches to Bilingualism, 7(3), 331-358.https://doi.org/10.1075/lab.15019.alm

Altinkamis, F., \& Simon, E. (2020). Language abilities in bilingual children: the effect of family background and language exposure on the development of Turkish and Dutch. International Journal of Bilingualism, 24(5-6), 931-951. https://doi.org/10.1177/ 1367006920909889

Bedore, L., \& Pena, E. D. (2008). Assessment of bilingual children for identification of language impairment: current findings and implications for practice. International Journal of Bilingual Education and Bilingualism, 11(1), 1-29. https://doi-org.fgul.idm.oclc.org/10.2167/ beb392.0

Bohnacker, U., Lindren, J., \& Oztekin, B. (2016). Turkish- and Germanspeaking bilingual 4-to-6 year olds living in Sweden: effects of age, SES and home language input on vocabulary production. Journal of Home Language Research, 1, 17-41. https://doi.org/10.16993/jhlr.26

Duncan, T. S., \& Paradis, J. (2018). How does maternal education influence the linguistic environment supporting bilingual language development in child second language learners of English? International Journal of Bilingualism, 24(1), 46-61 https://doi.org/10. $1177 / 1367006918768366$.

Kids Count Data Center (2018, January 11). Kids Count. https:// datacenter.kidscount.org/updates/show/184-the-number-of-bilingualkids-in-america-continues-torise\#: :text=In\%202016\%2C\%2022\%25\% 20of\%20children,kids\%2C\%20in\%20the\%20last $\% 20$ decade.

Paradis, J. (2010). Bilingual children's acquisition of English verb morphology: effects of language exposure, structure complexity, and task type. Language Learning, 60(3), 651-680. : https://doi.org/10.1111/j. 1467-9922.2010.00567.x

Thordardottir, E., Rothenberg, A., Rivard, M. E., \& Naves, R. (2006). Bilingual assessment: can overall proficiency be estimated from separate measurement of two languages? Journal of Multilingual Communication Disorders, 4(1), 1-21. https://doi-org.fgul.idm.oclc.org/10.1080/ 14769670500215647

Unsworth, S. (2013). Assessing the role of current and cumulative exposure in simultaneous bilingual acquisition: the case of Dutch gender. Bilingualism: Language and Cognition, 16(1), 86-110. https://doi.org/ $10.1017 / \mathrm{S} 1366728912000284$

\section{AAPdN 2021}

Title: Neurological Effects of Dyslexia Treatments and Potential for Transfer

Presenting/lead Author:

Temima D. Kermaier, M.S.Ed

tkermaier@email.fielding.edu

6513 Glenwick Ct., Baltimore, MD 21209

443-562-8445

Fielding Graduate University

Co-authors:

Kristine M. Jacquin, Ph.D.

kjacquin@ fielding.edu

2020 De La Vina Street

Santa Barbara, CA 93105

805-898

Fielding Graduate University

\section{Objectives:}

Our objectives were to determine whether (a) commonly used interventions for students with dyslexia affect neurological changes and (b) gains transfer when a child with dyslexia learns a second language.

\section{Discussion:}

Research examining the neurobiological basis of dyslexia implicates several areas of the brain in dyslexic impairments (Hasko et al., 2014; $\mathrm{Hu}$ et al., 2010; Lajiness-O'Neill et al., 2007). For an intervention to be effective, it would therefore need to either correct the neurobiological impairment or provide a compensatory strategy. Understanding which mechanism of change is utilized by common interventions can inform future treatment developments. Furthermore, the rising numbers of English language learners in the U.S. makes relevant the question of whether treatment gains transfer to a new language.

Interventions for dyslexia can be divided into three categories based on underlying theory. Treatments based on the balance model or temporal theory target neurological processes and affect empirically supported neurological changes (Bakker, 1992; Lajiness-O'Neill et al., 2007). Interventions that utilize explicit phonics/orthographic instruction have rarely been examined for their impact on neurological processes, although one study suggests there may be an impact (Hasko et al., 2014). Additionally, few studies have examined the transfer of acquired language skills to a second language. Existing studies suggest that transfer is dependent on similarities between the first and second language (van Viersen et al., 2017). However, intervention in a second language yields gains for first language skills (Mohamadzadeh et al., 2019). 


\section{Conclusions:}

Research suggests that common interventions for dyslexia may affect neurological changes. However, research has yet to examine the neurological impact of phonics/orthographic-based treatments and whether the neurological effects of treatments are sustained long term. Additionally, few studies have examined transfer of acquired skills to a second language. Future research should examine the long-term neurological effects of dyslexia treatments and their potential for transfer.

\section{References}

Bakker, D. J. (1992). Neuropsychological classification and treatment of dyslexia. Journal of Learning Disabilities, 25(2), 102-109. https://doi. org/10.1177/002221949202500203

Hasko, S., Groth, K., Bruder, J., Bartling, J., \& Schulte-Korne, G. (2014). What does the brain of children with developmental dyslexia tell us about reading improvement? ERP evidence from an intervention study. Frontiers in Human Neuroscience, 8. https://doi.org/10.3389/fnhum. 2014.00441

Hu, W., Lee, H. L., Zhang, Q., Liu, T., Geng, L. B., Seghier, M. L., Shakeshaft, C., Twomey, T., Green, D. W., Yang, Y. M., \& Price, C. J. (2010). Developmental dyslexia in Chinese and English populations: dissociating the effect of dyslexia from language differences. Brain, 133(6), 1694-1706. https://doi-org.fgul.idm.oclc.org/10.1093/brain/ awq106

Lajiness-O'Neill, R., Akamine, Y., \& Bowyer, S. M. (2010). Treatment effects of Fast ForWord demonstrated by magnetoencephalography (MEG) in a child with developmental dyslexia. Neurocase, 13(5-6), 390-401. https://doi-org.fgul.idm.oclc.org/10.1080/13554790701851544 Mohamadzadeh, S., Sotoudehnama, E., Marandi, S. S., \& Tafti, M. A. (2019). Teaching English to students with dyslexia in Iran: a multiplecase study. Reading \& Writing Quarterly, 36(1), 19-33. https://doi-org. fgul.idm.oclc.org/10.1080/10573569.2019.1605951

van Viersen, S., de Bree, E. H., Kalee, L., Kroesbergen, E. H., \& de Jong, P. F. (2017). Foreign language reading and spelling in gifted students with dyslexia in secondary education. Reading and Writing, 30(6), 1173-1192. https://doi.org/10.1007/s11145-016-9717-x

Authors: Courtney Larsen, B.S. (cmlarsen2@bsu.edu)

Andrew S. Davis, Ph.D. (davis@bsu.edu)

Address: 2000 W. University Ave., Teachers College 505, Muncie, IN 47306

Office Phone: $765-285-8500$

Office Fax: 765-285-3653

Affiliation: Ball State University

\section{A Review of the Validity of the Computer Assisted WISC-V}

\section{Objectives}

The Coronavirus pandemic has highlighted the need for, and accelerated, the development and advancement of virtual and computer-administered cognitive assessments. Pearson's Q-Interactive ${ }^{\circledR}$ can be used to administer the Wechsler Intelligence Scale for Children-Fifth Edition (WISC-V, Wechsler, 2014) during telehealth sessions by using an iPad and the iPad's screen sharing feature. Despite the increase in computer-assisted cognitive assessments, there are a limited number of peer-reviewed studies that elucidates the validity and reliability of this method. The purpose of this poster is to review the literature on the validity and reliability of computer-assisted cognitive assessment, specifically the WISC-V, and to make recommendations for future considerations.

\section{Data Selection}

A systemic search of peer-reviewed articles was conducted via the following databases: PsycINFO, PsycARTICLES, ERIC, and PubMed using combinations of the following search terms: 'Computerized Assessment' and 'Children' or 'adolescents' or 'youth' or 'child' or 'teenager' or 'pediatric' or 'paedetric' or 'kids' and 'Intelligence' or 'IQ' or 'cognitive ability.' The search yielded a total of 178 articles and nine were retained due to their discussion of computer-assisted Wechsler Intelligence Scales.

\section{Data Analysis}

The nine articles were reviewed and synthesized. Results were mixed regarding score differences between traditional and computer administration.

\section{Conclusions}

Results from current literature are inconclusive for whether the digital Wechsler Intelligence Scales are as statistically valid and reliable as the paper Weschler Intelligence Scales. Furthermore, the current literature is inconclusive on whether or not digital Weschler Intelligence Scales yield the same results as the paper version for clients across different domains such as ethnicity, SES, age, abilities, clinical conditions, and gender. This poster will discuss implications for researchers and practitioners.

\section{Do Nonverbal Tests Reduce Minoritized Disproportionality in Gifted Programs?}

Authors: Shalise Law B.S. (slaw@bsu.edu)

Maria Hernández Finch, Ph.D. (mefinch@bsu.edu)

Andrew S. Davis, Ph.D. (davis@bsu.edu)

Address: 2000 W. University Ave., Teachers College 505, Muncie, IN 47306

Office Phone: 765-285-8500

Office Fax: 765-285-3653

Affiliation: Ball State University

\section{Objectives}

To address underrepresentation of minoritized students in gifted programs, some psychologists employ nonverbal intelligence tests to assess students' aptitude. Nonverbal intelligence measures are believed to be less culturally loaded than traditional tests. However, the research on the efficacy of these to address disproportionality is limited. This poster aims to clarify the efficacy of three nonverbal tests commonly used with under-represented students.

\section{Data Selection}

The literature was collected from the databases: PsycINFO, PsycArticles, ERIC, and MEDLINE using the search terms 'gifted,' and 'race or ethnicity or minority or Hispanic or Latino or Latina or Latinx or African American or Black or Native American or Indigenous or Pacific Islander,' and 'nonverbal test or nonverbal assessment.' This search produced 35 peer-reviewed articles published between 1988 and 2020, and 20 were retained as relevant to the use of nonverbal assessment for gifted identification in minoritized populations.

\section{Data Analysis}

The remaining 20 articles were reviewed and evaluated. Of the 20 articles, nine were empirical studies, six were responses to previously published papers, one was a meta-analysis, and four provided additional commentary. The three tests most commonly referenced include neuropsychological measures (e.g., NNAT, CogAT®, and Raven's).

\section{Conclusions}

Analysis of the extant literature suggests that no single test was effective at reducing the disproportionality across all gifted underrepresented populations. Considerations for pediatric neuropsychologists revealed include awareness of varying gifted definitions, unequal opportunity to learn, predictive validity, construct underrepresentation, arbitrary cut-scores, and the confounding effects of intersectionality. Nonverbal tests used with universal screening, dynamic assessment, and local/group norms better addressed proportionality. Neuropsychologists seeking to improve outcomes after identification should consider how evaluation recommendations can enhance retention of under-represented students in gifted programming. Future needed research in nonverbal gifted assessment will be discussed including consideration of Cognitive Academic Language Proficiency (CALP) scores and using nonverbal assessment for twice-exceptional students. 


\section{Authors:}

Sandra Loza, B.S.

sloza@alliant.edu

1000 S. Fremont Avenue, Bldg A-7, Alhambra, CA 91803

Phone: (951) 375-9114

California School of Professional Psychology at Alliant International University

Grace Mucci, Ph.D., M.S., ABPdN

gmucci@choc.org

1201 West La Veta Avenue, Suite 470, Orange, CA 92868

Phone: (714) 509-8481

Fax: (714) 509-8756

CHOC Children's Hospital

Title: Neurobehavioral Effects of COVID-19 in the Context of Langerhans Cell Histiocytosis $(\mathrm{LCH})$ in a 5-Year-Old Boy: a Case Study

Objective: Langerhans Cell Histiocytosis (LCH) is a rare disease typically diagnosed in children ages $2-3$. The etiology is unknown but about half of LCH cases have mutations of the BRAF gene and are associated with the abnormal buildup of immature white blood cells (Langerhans cells) resulting in granulomatous tumors in one or multiple organ systems of the body, including the central nervous system. There is no literature on the co-morbid effects of COVID-19 and LCH. COVID-19 is a viral infection known to cause inflammation in the brain in children with possible long-term effects after recovery. This case study of a five-year-old male with $\mathrm{LCH}$, diagnosed at age 3 , with a small resected $3.3 \times 1 \mathrm{~cm}$ right parietal lesion, was treated with one year of chemotherapy with no complications. This patient was previously diagnosed with ADHD and contracted COVID-19 which may have intensified ADHD symptoms. This case study provides insights into the comorbidity between $\mathrm{LCH}-$ COVID-19.

Method: Neuropsychological evaluation was conducted on a 5-year-old boy with a history of $\mathrm{LCH}$ and a recent COVID-19 infection. He underwent a full battery examining intelligence, academic skills, attention/executive function, language, memory, visual processing, and behavioral/emotional functioning.

Results: Mental status examination revealed separation anxiety and impulsivity/hyperactivity. Neurocognitive assessment revealed low average intellectual functioning, with significant attention, language, phonological, verbal learning/memory, and visuomotor deficits, with notable academic achievement difficulties. Visuospatial and visual memory abilities were largely intact. Behavioral measures revealed significant externalizing and behavioral symptoms, with difficulties with behavioral and emotional regulation.

Conclusion: Results indicated neurocognitive deficits in attention, behavioral regulation, and language processing. The child's behavioral dysregulation was likely exacerbated by the recent COVID-19 infection, and future research should continue to examine the trajectory of neurocognitive deficits associated with COVID-19 and LCH pathology.

\section{REFERENCES:}

Condie, L. O. (2020). Neurotropic mechanisms in COVID-19 and their potential influence on neuropsychological outcomes in children. Child Neuropsychology, 26(5), 577-596.

Kim, Y., Walser, S. A., Asghar, S. J., Jain, R., Mainali, G., \& Kumar, A. (2020). A comprehensive review of neurologic manifestations of COVID-19 and management of pre-existing neurologic disorders in children. Journal of Child Neurology, 0883073820968995.

Rarediseases.info.nih.gov. 2021. Langerhans cell histiocytosis | Genetic and Rare Diseases Information Center (GARD) - an NCATS Program. [online] Available at: <https://rarediseases.info.nih.gov/diseases/6858/ langerhans-cell-histiocytosis $>$ [Accessed 31 January 2021].

Shuper, A., Stark, B., Yaniv, Y., Zaizov, R., Carel, C., Sadeh, M., \& Steinmetz, A. (2000). Cerebellar involvement in Langerhans' cell histiocytosis: a progressive neuropsychiatric disease. Journal of Child Neurology, 15(12), 824-826. https://doi.org/10.1177/ 088307380001501214

Authors: Carly McDonald, M.A. (cgmcdonald@bsu.edu)

Andrew S. Davis, Ph.D. (davis@bsu.edu)

Address: 2000 W. University Ave., Teachers College 505, Muncie, IN 47306

Office Phone: 765-285-8500

Office Fax: 765-285-3653

Affiliation: Ball State University

The Identification of Gifted Students with Specific Learning Disabilities

\section{Objectives}

Gifted students with learning disabilities (G/LD) exhibit a unique pattern of cognitive strengths and weaknesses that set them apart from students who are only gifted or have disabilities (Ottone-Cross et al., 2017). The matter is complicated by the fact that there is little consensus on diagnostic/identification, meaning that a student who is identified as G/LD in one setting may not meet the criteria in another. This is problematic, as it increases the risk of delayed identification and academic failure (Gilman et al., 2013). The purpose of this literature review is to analyze and discuss the criteria currently being used to identify G/LD students.

\section{Data Selection}

The literature review was conducted by searching the following databases: Academic Search Complete, ERIC, MEDLINE with full text, PsycARTICLES, and PsychINFO. Search terms included "twice exceptional or 2e," "gifted students or gifted or gifted children or giftedness," "learning disabilities," and "identification." In total, 110 peer-reviewed journal articles met the search criteria. Articles were excluded if they were published prior to 2000 or not related to G/LD identification; 15 articles were retained based on their relevance to the topic.

\section{Data Analysis}

The 15 relevant articles were reviewed and synthesized. Each article was examined to determine which assessments were administered, what cutoff scores were used, and implications for best practices.

\section{Conclusions}

Researchers identified G/LD students using a variety of assessments, including the Woodcock Johnson Tests of Cognitive Abilities and Tests of Achievement (3rd and 4th Editions), Wechsler Intelligence Scale for Children (4th and 5th Editions), and Kaufman Test of Educational Achievement (3rd Edition). The criteria varied widely across articles, revealing a lack of consensus on how to identify G/LD students. This poster will discuss the implications for researchers and practitioners.

\section{Authors:}

\section{Matthew Pagirsky, PsyD}

MPagirsky@quadprep.org

Director of Psychology Training and Education, Senior Upper School Psychologist

The Quad Preparatory School

25 Pine Street, Floor 4

New York, NY 10005

646-649-3913

Tess Osborne

tosborne@quadprep.org

Research Assistant

The Quad Preparatory School

25 Pine Street, Floor 4

New York, NY 10005

646-649-3913

Carly Rossman, M.S., CCC-SLP

crossman@quadprep.org

Senior Speech Language Pathologist

Pronouns: she/her/hers 
The Quad Preparatory School

25 Pine Street, Floor 4

New York, NY 10005

646-649-3913 ex. 436

Jessica Sherry, M.S., CCC-SLP

jsherry@quadprep.org

Upper School Speech-Language Pathologist

The Quad Preparatory School

25 Pine Street, Floor 4

New York, NY 10005

646-649-3913

Nancy Tarshis MA, MS CCC/SLP

ntarshis@quadprep.org

Director Early Elementary Program

The Quad Preparatory School

25 Pine Street, Floor 4

New York, NY 10005

646-649-3913

Emily Vizza, M.S., CCC-SLP

Director of Clinical Affairs

The Quad Preparatory School

25 Pine Street, Floor 4

New York, NY 10005

646-649-3913 ext. 17

\section{The Social Thinking-Social Communication Profile (ST-SCPTM) of Twice-Exceptional (2e) Students}

\section{Objective}

The Social Thinking-Social Communication Profile (ST-SCPTM; Winner, Crooke, Madrigal, 2016) was developed to conceptualize and understand changes resulting from intervention in students with social communication difficulties. While this tool has received positive feedback from practitioners, there has been limited research on its utility. The present study aimed to provide preliminary validation of the ST-SCPTM and additional insights into the social communication and social cognitive profiles of Twice Exceptional (2e) students.

Methods

Data was collected from 43 students at an independent special education school for $2 \mathrm{e}$ children. All students in the sample underwent a comprehensive neuropsychological assessment and the Social Thinking ${ }^{\mathrm{TM}}$ Dynamic Assessment. In addition, parent questionnaires (SRS-2, CCC2) were completed.

Results

Preliminary descriptive analyses revealed the mean sample age was $9.40(5-17)$ and the mean Full-Scale IQ on the WISC-V was 125 (102-153). Most of the sample (34\%) fell into the Weak Interactive Social Communication (WISC) profile. About a quarter of the sample $(25 \%)$ met criteria for the Strong Emerging Social Communication (S-ESC) profile. The sample's social competency characteristics, as assessed by the SRS-2, yielded the highest mean scores on the Restricted Interests and Repetitive Behaviors subscale, followed by the Social Awareness, and Social Communication subscales. As noted, further analyses will be conducted comparing these profiles on the various standardized measures completed.

Conclusion

Given the dearth of research on the ST-SCPTM and the social communication and social cognitive profiles of $2 \mathrm{e}$ students, this study provides significant insight into the characteristics of this sample of students. Ultimately, the goal is to help inform practitioners in school and clinical settings design appropriate intervention plans. Initial analyses reveal these students may display adequate social skills "on the surface," but have more nuanced and underlying social communication difficulties that impair their functioning.
References:

Garcia Winner, M., Crooke, P., Madrigal, S. (2015). The Social Thinking-Social Communication Profile ${ }^{\mathrm{TM}}$ - Levels of the social mind. Social Thinking. https://www.socialthinking.com/Articles?name=socialthinking-social-communication-profile

Garcia Winner, M., Crooke, P., Madrigal, S. (2016). Social Thinking ${ }^{\mathrm{TM}}$ Social Communication Profile (Characteristics summary) instructions. Social Thinking. https://www.socialthinking.com/-/media/Files/ Conference-Handouts/ST-SCP-Characteristic-Summary-Instructions. ash $x$ la $=$ en.

Treatment of Sports Related Concussions in Female Adolescent Athletes

Neda Petz, Psy.D.

Equip Psychology

2006 Cañada Blvd.

Glendale, CA 91208

818.268.2665

nedapetz@gmail.com

Denise Rockwell, Ph.D., BCBA-D

Rockwell Psychological Services Corp

1555 Campus Rd

Los Angeles, CA 90042

818.350 .2323

deniserockwellphd@gmail.com

Kenneth Hartline, Psy.D., ABPP-CN

Division of Neurology, Children's Hospital Los Angeles

Keck School of Medicine, University of Southern California

323.361.5265

khartline@chla.usc.edu

Sports-related concussions (SRCs) have been referred to as one of the most multifaceted and poorly understood injuries in sports medicine to diagnose and manage (McCrory et al., 2017). Notably, the management in SRCs is particularly challenging since data demonstrates that high school and collegiate level athletes are more likely to exhibit a delayed onset of symptoms as well as neuropsychological deficits that may not be present on the sideline (West \& Marion, 2014).

This topic is especially relevant to female adolescent athletes due to the steady increase of their participation in sports, which has begun to substantially close the gender gap in sports membership (NFHS, 2018). Although SRCs are increasing among female adolescent athletes, the comparative consequences of male and female athletes are poorly understood, resulting in limitations in a scientific understanding and ensuing treatment of these injuries (Sicard, Moore, \& Ellemberg, 2018). Despite the significance of this topic, there is a gap in the literature, with the majority of concussion research centered on male collegiate athletes and a paucity of individualized treatment methods that address the specific emotional, developmental, and physical needs of the female adolescent population.

The purpose of this poster is to provide a critical review of the literature concerning gender differences pertaining to sports-related concussions in female adolescent athletes, identify treatment gaps in the literature, and provide recommendations for best practices in treating this population. The goal is to provide practitioners working with this population with targeted recommendations in order to improve the treatment and recovery of adolescent female athletes.

\section{References}

McCrory, P., Meeuwisse, W., Dvorak, J., Aubry, M., Bailes, J., Broglio, S., ... \& Davis, G. A. (2017). Consensus statement on concussion in sport - the 5th international conference on concussion in sport held in Berlin, October 2016. Br J Sports Med, bjsports-2017. doi: 10.1136/ bjsports-2017-097699 
National Federation of State High School Associations. (2018). High School Sports Participation Increases for $29^{\text {th }}$ Consecutive Year. Retrieved from https://www.nfhs.org/articles/high-school-sportsparticipation-increases-for-29th-consecutive-year/

Sicard, V., Moore, R. D., \& Ellemberg, D. (2018). Long-term cognitive outcomes in male and female athletes following sport-related concussions. International journal of psychophysiology, 132, 3-8. doi: https:// doi.org/10.1016/j.ijpsycho.2018.03.011

West, T. A., \& Marion, D. W. (2014). Current recommendations for the diagnosis and treatment of concussion in sport: a comparison of three new guidelines. Journal of Neurotrauma, 31(2), 159-168. doi: https://doi.org/ 10.1089/neu.2013.3031.

\section{The Use and Efficacy of Methylphenidate to Treat Pediatric TBI Sequelae}

Authors: Kelsey Pscheid, M.A., CBIS (kpscheid@bsu.edu)

Andrew S. Davis, Ph.D. (davis@bsu.edu)

Address: 2000 W. University Ave., Teachers College 505, Muncie, IN 47306

Office Phone: 765-285-8500i

Office Fax: 765-285-3653

Affiliation: Ball State University

\section{Objectives}

Common pediatric traumatic brain injury (TBI) sequelae include problems with memory, attention, concentration, and decision-making, all of which are also associated with attention-deficit hyperactivity disorder (ADHD). Indeed, children who have sustained a TBI are at an increased risk for developing ADHD secondary to their injury (Narad, et al., 2018), so it is important for clinicians to understand effective treatment options. For example, pediatric patients may be treated with neurostimulant medication such as methylphenidate. Neurostimulants are commonly prescribed for adults after TBI, but, less is known regarding the use of neurostimulants in the pediatric population as evidenced by the limited literature base regarding their use relative to the adult literature. Despite the increased prevalence of ADHD after pediatric TBI, relatively little research investigates the efficacy and use of medications for treatment. The purpose of this poster is to review the existing literature regarding the efficacy, safety, side effects, and use of methylphenidate for treatment of pediatric TBI sequelae.

\section{Data Selection}

Literature was obtained via searches of journals available in the following databases: PsycINFO, PsycARTICLES, MedLine using combinations of the following search terms: 'traumatic brain injury' or 'head injury,' or 'brain injury' or 'TBI' and 'children' or 'adolescents' or 'youth' or 'child' or 'teenager' or 'teens' or 'young people' or 'kids' or 'pediatric' and 'methylphenidate.' A total of 60 articles were found with 15 related to the use of methylphenidate as treatment of TBI sequelae and secondary ADHD in a pediatric sample.

Data Analysis

The 15 related articles were reviewed and synthesized.

Conclusions

Synthesis of current research generally supports the use of methylphenidate for treatment of ADHD symptoms secondary to pediatric TBI. Most, but not all, clinical trials found slight to moderate improvement in attention, memory, and processing speed. This poster will discuss the implications for researchers and practitioners.

POSTER PROPOSAL TITLE: Child Sexuality, Cyber Behavior, and Neurological Development

LEAD AUTHOR: Janine M. Ray M.A., jray@email.fielding.edu, 1031371 Fir Street, White Rock, BC V4B 4B3 CANADA, 778-928-0741

CO-AUTHORS: Polina Kats-Kariyanakatte M.S., pkatskariyanakatte@email.fielding.edu, 1333 School Lane, Rydal, PA 19046,
412-656-3453; Sarah Chernoff M.B.A, schernoff@email.fielding.edu, 205 Hunters Place Okotoks AB T1S1K8 CANADA, 587-225-7344; Kristine M. Jacquin PhD., kjacquin@fielding.edu, 2020 De La Vina Street, Santa Barbara, CA 93105, 805-898-2949

AFFILATION: Fielding Graduate University, 2020 De La Vina Street, Santa Barbara, CA 93105, 805-898-2949

\section{SUMMARY}

Submission information - 300 words:

\section{OBJECTIVES:}

Exposure to and engagement in sexual interactions occurs frequently at younger ages (Lewis, 2018). Online offences of sexual abuse are as harmful as those committed offline (Salter, 2016; Wolak \& Finkelhor, 2013). Empirical study into brain development of prepubescents regarding their sexual awareness and interests, and the implications of these within the context of access to online communications, is absent.

\section{DISCUSSION:}

Neurobiological influences on child behavior reflect limited empathy and increased risky behaviors (Bowker \& Sullivan, 2010). Children are susceptible to media, entertainment sources, and celebrity culture (Angelides, 2013). These often sexually based stimuli may be mimicked in child behavior and language (Holfeld \& Leadbeater, 2015).

Prepubescent children have sexual feelings (Walker et al., 2013). However, younger-child sexuality is a socially sensitive issue on many fronts (Lumby, 2020; Sparrman, 2014). Nonetheless, the emerging sexual urges and curiosities of prepubescents, combined with their proclivity to mimic and act impulsively, strengthen the potential for harm.

Ignoring child sexuality creates challenges within their increasingly online lifestyles (Pluhar et al., 2008). Children can mistakenly interpret online spaces as environments lacking repercussions (Wyckoff et al., 2019). This ever-available social space can offer prepubescents, with peaking sexuality and developing brains, platforms for sexual communications (Miller \& Morris, 2016). Although children should not be shamed for sexual feelings, they can be guided in a way that is developmentally appropriate.

\section{CONCLUSIONS:}

There remains limited discussion regarding prepubescent sexual feelings, behavior, and online communication. More research into neurological influences on child sexuality is required. Developmentally appropriate interventions may reduce societal stigma and instead support children, parents, teachers, and communities in navigating this sensitive topic.

\section{REFERENCES:}

Angelides, S. (2013). Technology, hormones, and stupidity: the affective politics of teenage sexting. Sexualities, 16(5-6), 665-689. https://doi.org/ $10.1177 / 1363460713487289$

Bowker, A., \& Sullivan, M. (2010). Sexting risky actions and overreactions. FBI Law Enforcement Bulletin, 79(7), 27-31.

Bronfenbrenner, U. (2004). Making human beings human: bioecological perspectives on human development. Sage Publications.

Bushway, S. D., Piquero, A. R., Broidy, L. M., Cauffman, E., \& Mazerolle, P. (2001). An empirical framework for studying desistance as a process. Criminology, 39(2), 491-516. https://doi.org/10.1111/j. 1745-9125.2001.tb00931.x

Caldwell, M. F. (2002). What we do not know about juvenile sexual reoffense risk. Child Maltreatment, 7(4), 291-302. https://doi.org/10. 1177/107755902237260

Dietrich D, Olson M. (1993). A demonstration of hindsight bias using the Thomas confirmation vote. Psychological Reports, 72(2), 377-378. https://doi.org/10.2466/pr0.1993.72.2.377

Erlbaum,W., Joy P., Buss, David M., \& Markman, Arthur B. (2019). Sex differences in victimization and consequences of cyber aggression: an evolutionary perspective. Evolutionary Behavioral Sciences, 13(3), 254264. https://doi.org/10.1037/ebs0000150

Hanson, R. K., Harris, A.J.R., Letourneau, E., Helmus, L. M., \& Thornton, D. (2018). Reductions in risk based on time offense-free in 
the community: once a sexual offender, not always a sexual offender. Psychology, Public Policy, and Law, 24(1), 48-63. https://doi.org/10. 1037/law0000135

Holfeld, B., \& Leadbeater, B.J. (2015). The nature and frequency of cyber bullying behaviors and victimization experiences in young Canadian children. Canadian Journal of School Psychology, 30(2), 116-135. https:// doi.org/10.1177/0829573514556853

Lewis, R. (2018). Literature review on children and young people demonstrating technology assisted harmful sexual behavior. Aggressive and Violent Behavior, 40, 1-11. https://doi.org/10.1016/j.avb.2018.02.011

Lumby, C. (2010). Ambiguity, children, representation, and sexuality. CLCWeb: Comparative Literature and Culture, 12(4) https://doi.org/ 10.7771/1481-4374.1673

Miller, B., \& Morris, R. G. (2016). Virtual peer effects in social learning theory. Crime \& Delinquency, 62(12), 1543-1569. https://doi.org/10. 1177/0011128714526499

Nagin, D. S., Farrington, D. P., \& Moffitt, T. E. (1995). Life-course trajectories of different types of offenders. Criminology, 33(1), 111-139. Omar, S., \& Patel, L. (2014). Child-on-child sexual abuse: results of a survey in Johannesburg. Social Work/Maatskaplike Werk, 48(3) https:// doi.org/10.15270/48-3-85

Pluhar, E. I., Dilorio, C. K., \& McCarty, F. (2008). Correlates of sexuality communication among mothers and 12-year-old children. Child: Care, Health and Development, 34(3), 283-290. https://doi.org/10.1111/j.13652214.2007.00807.x

Quayle, E. (2007). Assessment issues with young people who engage in sexually abusive behaviors through new technologies. In M. C. Calder (Ed.), Working with Children and Young People Who Sexually Abuse: Taking the field forward (pp. 217-229). Russell House Publishing Limited.

Raisi, E., \& Huang, B. (2018). Weakly supervised cyberbullying detection with participant-vocabulary consistency. Social Network Analysis and Mining, 8(1), 1-17. https://doi.org/10.1007/s13278-018-0517-y

Rao, V. (2012). Children who sexually abuse other children. A survey of young and teenage sexual offenders over a 10-year period. Archives of Disease in Childhood, 97, A97-A97. https://doi.org/10.1136/ archdischild-2012-301885.230

Reed, L. A., Tolman, R. M., \& Ward, L. M. (2016). Snooping and sexting: digital media as context for dating aggression and abuse among college students. Violence Against Women, 22(13), 1556-1576. https:// doi.org/10.1177/1077801216630143

Renold, E., \& Ringrose, J. (2016). Selfies, relfies and phallic tagging: Posthuman participations in teen digital sexuality assemblages. Educational Philosophy and Theory, 1469-5812. https://doi.org/10. 1080/00131857.2016.1185686

Salter, M., Crofts, T., \& Lee, M. (2013). Beyond criminalisation and responsibilisation: sexting, gender and young people. Current Issues in Criminal Justice 24(3): 301-316. https://doi.org/10.1080/10345329. 2013.12035963

Sauerteig, L. D. (2012). Loss of innocence: Albert Moll, Sigmund Freud and the invention of childhood sexuality around 1900. Medical History, 56(2), 156-183. https://doi.org/10.1017/mdh.2011.31

Sparrman, A. (2014). Access and gatekeeping in researching children's sexuality: mess in ethics and methods. Sexuality \& Culture, 18(2), 291309. https://doi.org/10.1007/s12119-013-9198-x

Tyler, K. A., Hoyt, D. R., \& Whitbeck, L. B. (2000). The effects of early sexual abuse on later sexual victimization among female homeless and runaway adolescents. Journal of Interpersonal Violence, 15(3), 235-250. https://doi.org/10.1177/088626000015003001

Wyckoff, J.P., Buss, D.M., \& Markman, A. B. (2019). Sex differences in victimization and consequences of cyber aggression: an evolutionary perspective. Evolutionary Behavioral Sciences, 13(3), 254-264. https://doi. org/10.1037/ebs0000150
American Academy of Pediatric Neuropsychology 2021- Original Research Abstract

Title:

Childhood emotional abuse and negative self-perceptions predict adult emotion dysregulation

Presenting Author:

ShawnMarie Rehfeld, M.A., srehfeld@email.fielding.edu, 16611 Meridian Avenue North, Shoreline, WA, 98133; (206) 778-8845; Fielding Graduate University, Santa Barbara, CA

Co-authors:

Holly N. Summers, M.A., hsummers@email.fielding.edu, 3005 Blush Noisette Avenue, North Las Vegas, NV, 89081; (702) 409-4797; Fielding Graduate University, Santa Barbara, CA

Kristine M.Jacquin, Ph.D.,kjacquin@fielding.edu, kjacquin@fielding.edu, 805-898-2949, Fielding Graduate University, 2020 De La Vina Street, Santa Barbara, CA 93105

\section{Objectives}

Childhood maltreatment may affect executive functions involved in emotion regulation (Gruhn et al., 2020; Kraus-utz et al., 2019; Weissman et al., 2019). Childhood emotional abuse (CEA; conveying to a child that they are unloved) and childhood emotional neglect (CEN; passive omission of nurturance to a child; Taillieu et al., 2016) negatively influence a child's cognitive self-perception (Appleyard et al., 2010). We hypothesized that negative self-perceptions (NSP) in childhood would moderate the relationship between childhood emotional maltreatment and adult emotion regulation later in life.

\section{Methods}

Participants $(N=481 ; M$ age $=35.74$ years, $\mathrm{SD}=9.82 ; 59 \%$ female, $40.7 \%$ male, $0.2 \%$ other; $77.1 \%$ Caucasian) completed three measures as part of an online survey in Qualtrics. The Perceptions of Self in the World (Davis, 2017), reflecting Erik Erickson's eight psychosocial developmental stages, measured NSP associated with the Autonomy vs. Shame/ Doubt stage, the Childhood Trauma Questionnaire-Short Form (Bernstein et al., 2003) examined CEA and CEN, and the Difficulties in Emotional Regulation Scale (Gratz \& Roemer, 2004) measured adult emotion dysregulation.

\section{Results}

As predicted, both CEA and CEN significantly correlated with adult emotion dysregulation $r(481)=.756, p<.001$. NSP moderated the relationship between CEA and adult emotion dysregulation, $b=0.91$, $S E=.040,95 \% \mathrm{CI}=[.012, .170], t=2.273, p=.0235$, whereas CEN and adult emotion dysregulation were not moderated by NSP, $b=.015$, $S E=.039,95 \% \mathrm{CI}=[-.062, .092] t=.385, p=.7004$.

\section{Conclusions}

Our results show children who experience CEA and have negative selfperceptions are at increased risk to be emotionally dysregulated in adulthood. Findings suggest pediatric neuropsychologists should assess emotion regulation in children who experience CEA. Cognitive therapies may be helpful to address self-perceptions and executive function strategies effective in emotion regulation to improve long-term childhood outcomes.

\section{References}

Appleyard, K., Yang, C., \& Runyan, D. K. (2010). Delineating the maladaptive pathways of child maltreatment: a mediated moderation analysis of the roles of self-perception and social support. Development and Psychopathology, 22(2), 337-352. https://doi.org/10.1017/ s095457941000009x

Bernstein, D. P., Stein, J. A., Newcomb, M. D., Walker, E., Pogge, D., Ahluvalia, T., Stokes, J., Handelsman, L., Medrano, M., Desmond, D., \& Zule, W. (2003). Development and validation of a brief screening version of the childhood trauma questionnaire. Child Abuse \& Neglect, 27(2), 169-190. https://doi.org/10.1016/s0145-2134(02)00541-0 
Davis, A. S. (2018). Perceptions of Self in the World (Perceived Social Support, Affect Regulation, and Self-Awareness Mediate the Relationship Between Childhood Trauma and Self-Efficacy). Fielding Graduate University.

Dennis, T. A. (2010). Neurophysiological markers for child emotion regulation from the perspective of emotion-cognition integration: current directions and future challenges. Developmental Neuropsychology, 35(2), 212-230. https://doi.org/10.1080/87565640903526579

Erikson, E. H. (1994). Identity and the life cycle (1st ed.). W. W. Norton. Gratz, K. L., \& Roemer, L. (2004). Multidimensional assessment of emotion regulation and dysregulation: development, factor structure, and initial validation of the difficulties in emotion regulation scale. Journal of Psychopathology and Behavioral Assessment, 26(1), 41-54. https://doi. org/10.1023/b:joba.0000007455.08539.94

Gruhn, M. A., \& Compas, B. E. (2020). Effects of maltreatment on coping and emotion regulation in childhood and adolescence: a metaanalytic review. Child Abuse \& Neglect, 103, 104446. https://doi.org/ 10.1016/j.chiabu.2020.104446

Krause-Utz, A., Erol, E., Brousianou, A. V., Cackowski, S., Paret, C., Ende, G., \& Elzinga, B. (2019). Self-reported impulsivity in women with borderline personality disorder: the role of childhood maltreatment severity and emotion regulation difficulties. Borderline Personality Disorder and Emotion Dysregulation, 6(1). https://doi.org/10.1186/s40479-0190101-8

Spinhoven, P., Elzinga, B. M., Van Hemert, A. M., de Rooij, M., \& Penninx, B. W. (2016). Childhood maltreatment, maladaptive personality types and level and course of psychological distress: a six-year longitudinal study. Journal of Affective Disorders, 191, 100-108. https://doi.org/ 10.1016/j.jad.2015.11.036

Taillieu, T. L., Brownridge, D. A., Sareen, J., \& Afifi, T. O. (2016). Childhood emotional maltreatment and mental disorders: results from a nationally representative adult sample from the united states. Child Abuse \& Neglect, 59, 1-12. https://doi.org/10.1016/j.chiabu.2016.07.005 van Harmelen, A.-L., de Jong, P. J., Glashouwer, K. A., Spinhoven, P., Penninx, B. W., \& Elzinga, B. M. (2010). Child abuse and negative explicit and automatic self-associations: the cognitive scars of emotional maltreatment. Behaviour Research and Therapy, 48(6), 486-494. https:// doi.org/10.1016/j.brat.2010.02.003

Weissman, D. G., Bitran, D., Miller, A., Schaefer, J. D., Sheridan, M. A., \& McLaughlin, K. A. (2019). Difficulties with emotion regulation as a transdiagnostic mechanism linking child maltreatment with the emergence of psychopathology. Development and Psychopathology, 31(3), 899-915. https://doi.org/10.1017/s0954579419000348

\section{Early Prediction of Psychosis: Neurodevelopmental Markers Among Children and Youth}

Jaqueline Rossi Green, B.A. and Kristine M. Jacquin, Ph.D.

Fielding Graduate University

Poster for Presentation Proposal for AAPdN 2021

Title: Early Prediction of Psychosis: Neurodevelopmental Markers Among Children and Youth

Authors: Jaqueline Rossi Green, B.A., \& Kristine M. Jacquin, Ph.D Presenting Author: Jaqueline Rossi Green, B.A., Fielding Graduate University, 2020 De La Vina Street, Santa Barbara, CA 93105, 805898-2949,jdacosta@email.fielding.edu

Co-author: Kristine M. Jacquin, Ph.D., Fielding Graduate University, 2020 De La Vina Street, Santa Barbara, CA 93105, 805-898-2949, kjacquin@fielding.edu

\section{Summary:}

Research on psychosis in children and adolescents is scarce (Dolz et al., 2018; Spada et al., 2018). Advances in the scientific arena have indicated that patients who have been diagnosed with psychosis early on have better chances to improve their quality of life (Addington \& Heinssen, 2012; Dolz et al., 2018; Fusar-Poli et al.,
2012; Fusar-Poli \& Van Os, 2013; NAMI, 2020). The purpose of this poster presentation is to examine factors associated with early prediction of psychosis.

Schizophrenia has been associated with premorbid developmental impairments and familial risk factors (Nicolson et al., 2000). A study by Nicholson et al. (2000) looked at premorbid development such as language abnormalities, motor impairments, social dysfunctions, and familial psychopathology in children and adolescents that developed schizophrenia later in life. The association for the risk factors might be mediated partially by abnormal neurodevelopmental language areas of the brain (Nicholson et al., 2000).

Fusar-Poli et al. (2012) suggested that the majority of individuals who are at a clinical high risk of psychosis develop a psychotic disorder over time. The authors conducted a meta-analysis looking at the cognitive functioning $(\mathrm{CF})$ in prodromal psychosis and suggested that deficits in CF may predate the onset and might serve as indicators for increased psychosis vulnerability. Dolz at al. (2018) revealed that a group of children and adolescents predisposed to genetic risk criteria contributed to the development of psychosis. The study pointed out the importance of evaluating family history markers and neurodevelopmental indicators for early detection of psychosis

A prodromal phase usually precedes the onset of psychosis. Early preventative interventions should be feasible in this phase (Fusar-Poli \&Van Os, 2013). Identifying early on evidenced-based assessments and interventions for psychosis can significantly improve the lives of patients' education, professional, and personal lives.

\section{References}

Addington, J., \& Heinssen, R. (2012). Prediction and prevention of psychosis in youth at clinical high risk. Annual Review of Clinical Psychology, 8, 269-289. https://doi.org/10.1146/annurev-clinpsy032511-143146

Dolz, M., Tor, J., De la Serna, E., Pardo, M., Muñoz-Samons, D., Rodríguez-Pascual, M., Puig, O., Sugranyez, G., Usall, J., SanchèsGistau, V., \& Baeza, I. (2018). Characterization of children and adolescents with psychosis risk syndrome: the children and adolescents psychosis risk syndrome (capris) study. Early Intervention in Psychiatry. https:// doi.org/10.1111/eip. 12728

Fusar-Poli, P., Bonoldi, I., Yung, A. R., Borgwardt, S., Kempton, M. J., Valmaggia, L., Barale, F., Caverzasi, E., \& McGuire, P. (2012). Predicting psychosis: Meta-analysis of transition outcomes in individuals at high clinical risk. Archives of General Psychiatry, 69(3), 220-229. https://doi.org/10.1001/archgenpsychiatry.2011.1472

Fusar-Poli, P., Deste, G., Smieskova, R., Barlati, S., Yung, A. R., Howes, O., Stieglitz, R. D., Vita, A., McGuire, P., \& Borgwardt, S. (2012). Cognitive functioning in prodromal psychosis: a meta-analysis. JAMA Psychiatry, 69(6), 562-571.

Fusar-Poli, P., \& Van Os, J. (2013). Lost in transition: setting the psychosis threshold in prodromal research. Acta Psychiatrica Scandinavica, 127(3), 248-252. https://doi.org/10.1111/acps. 12028

Nicolson, R., Lenane, M., Singaracharlu, S., Malaspina, D., Giedd, J. N., Hamburger, S. D., Gochman, P., Bedwell, J., Thacker, G. K., Fernandez, T., Wudarsky, M., Homer, D. W., \& Rapoport, J. L. (2000). Premorbid speech and language impairments in childhoodonset schizophrenia: association with risk factors. The American Journal of Psychiatry, 157(5), 794-800. https://doi.org/10.1176/ appi.ajp.157.5.794

National Alliance of Mental Illness (NAMI). (2020). Understanding psychosis. https://sardaa.org/wp-content/uploads/2015/08/Nami Understanding_Psychosis_Booklet.pdf

Spada, G., Molteni, S., Pistone, C., Chiappedi, M., Mcguire, P., FusarPoli, P., \& Balottin, U. (2016). Identifying children and adolescents at ultra high risk of psychosis in italian neuropsychiatry services: a feasibility study. European Child \& Adolescent Psychiatry, 25(1), 91-106. https://doi.org/10.1007/s00787-015-0710-8 
Authors: Cameron A. Staudacher, BS (castaudacher@bsu.edu)

Andrew S. Davis, Ph.D. (davis@bsu.edu)

\section{The Neuropsychological Implications of Acute Respiratory Distress Syndrome in Children}

The COVID-19 pandemic has highlighted the medical implications of respiratory distress, specifically Acute Respiratory Distress Syndrome (ARDS), a broad term describing widespread inflammation in the lungs. Medical descriptors associated with severe respiratory distress have become commonplace, with terms such as "mechanical ventilation," "intubation," and "oxygen saturation" having entered the public lexicon. Awareness of chronic effects of respiratory distress is likely increasing, and the acute and potential iatrogenic physiological effects respiratory distress have been well studied in the pediatric population. Less attention, however, has been given to the neurocognitive late effects of respiratory distress, which can continue long after a patient has been discharged from the hospital and on their way to recovery. This poster will examine the neurocognitive portion of those possible long-term effects for children.

\section{Data Selection}

Literature was obtained via searches of journals available in the following databases: PsycINFO, PsycARTICLES, ERIC, NIH, ResearchGate, JSTOR, Medline and Academic Search Premier. Search terms included ('acute respiratory distress syndrome' or 'ARDS' or 'pediatric acute respiratory distress syndrome'), ('neurocognitive' or 'cognitive'), 'neurological,' 'neuro*,' 'cognit*,' 'development*,' and ('pediatric' or 'juvenile') There were 458 results that matched those search criteria. Of these, 16 were retained for their relevance.

Data Analysis

The 16 somewhat relevant articles were reviewed and synthesized.

\section{Conclusions}

This review will provide a brief overview of the current medical management of ARDS, the typical course of recovery, possible short- and longterm neurocognitive effects, and implications for pediatric neuropsychologists. While data describing the long-term effects of ARDS in children is lacking, it is likely that preemptive conclusions can be drawn from literature surrounding the adult population to demonstrate possible neurocognitive consequences of acute lung injury in children.

\section{Nurturing Neurons: Development of Telehealth Pediatric Support Network Promoting Wellbeing}

Laura Taglioni*, Kristen Laulette*, Brian Ng, Laura Lara, BA, Amy Lee, Madison Bresette, \& Grace Mucci, Ph.D.

*These authors contributed equally to the work.

Laura Taglioni: ltaglionichica@gmail.com, (917) 545-1091, University of California, Los Angeles.

Kristen Laulette: kristenlaulette@ gmail.com, (323) 717-9944, University of California, Los Angeles.

Brian Ng: brianng1208@yahoo.com, (626) 383-3983, University of California, Los Angeles.

Laura Lara, BA: lmusic.lara90@gmail.com, (559) 427-8079, Neuropsychology Services.

Amy Lee: alee.ca2017@gmail.com, (310) 738-3377, University of California, Los Angeles.

Madison Bresette: madisonbresette@gmail.com, 714-290-8023, University of California, Irvine.

Grace Mucci, Ph.D.: gmucci@npsyp.com, (714) 209-1706, Neuropsychology Services

Mailing address of all authors: Neuropsychology Services, 5855 East Naples Plaza, Suite 203, Long Beach, CA 90803.

Fax of all authors: 562.856.6004

Objectives: Amidst lockdowns, school closures, and social distancing, the COVID-19 pandemic has created a unique set of challenges for childhood development, such as increased fear in young children, school-related anxiety in adolescents, and difficulties for those with special needs (Singh et al., 2020). Considering this trajectory, the Nurturing Neurons program aims to integrate evidence-based practices into a digital program to increase mental wellness, emotional regulation, cognitive function, and social engagement in children K-12 presenting with sub-clinical concerns and neurodevelopmental conditions.

Discussion: Nurturing Neurons utilizes a multi-phased structure led by supervised paraprofessionals, broadening accessibility to clinical support. In phase 1, participants are first screened for psychological pathology that precludes them from participating. Remaining participants are grouped based on age and interests to form small, peersupported cohorts that meet twice weekly for six weeks. Curriculums are uniquely tailored to each group using core components that are efficacious for various concerns and promote cognitive and psycho-social functioning, including social activities (e.g., Yogman et al., 2018), mindfulness (e.g., Felver et al., 2017; Huguet et al., 2019), CBT (e.g., van Steensel \& Bögels, 2015; Asbrand et al., 2019), introspection (e.g. ,Flook et al., 2010), goal-setting (e.g., Schunk, 1991), and sensory breaks. Paraprofessionals undergo training, utilize engagement practices, and facilitate family communication. Progress and symptom severity will be measured with preand post-administration of the BASC-3 and PedsQL Generic Core Scales assessments. In phase 2, participants with continuing or worsening conditions are offered treatment

Conclusions: Successful mediation of psycho-social and cognitive determinants through Nurturing Neurons would influence neuropsychological research and clinical application of digital, group, and paraprofessionalfacilitated evidence-based practices on neurodiverse pediatric populations. Gathered data may contribute to findings on preventative measures for mental disorder onset and the implications of remote schooling, social isolation, and varied adversities on neurological and emotional development.

\section{References}

Asbrand, J., Schmitz, J., Krämer, M., Nitschke, K., Heinrichs, N., \& Tuschen-Caffier, B. (2019). Effects of group-based CBT on post-event processing in children with social anxiety disorder following an experimental social stressor. Journal of Abnormal Child Psychology, 47(12), 1945-1956. https://doi.org/10.1007/s10802-019-00558-x

Felver, J. C., Tipsord, J. M., Morris, M. J., Racer, K. H., \& Dishion, T. J. (2017). The effects of mindfulness-based intervention on children's attention regulation. Journal of Attention Disorders, 21(10), 872-881. https://doi.org/10.1177/1087054714548032

Flook, L., Smalley, S. L., Kitil, M. J., Galla, B. M., Kaiser-Greenland, S., Locke, J., Ishijima, E., \& Kasari, C. (2010). Effects of mindful awareness practices on executive functions in elementary school children. Journal of Applied School Psychology, 26(1), 70-95. https://doi.org/10.1080/ 15377900903379125

Huguet, A., Izaguirre Eguren, J., Miguel-Ruiz, D., Vall Vallés, X., \& Alda, J. A. (2019).

Deficient emotional self-regulation in children with attention deficit hyperactivity disorder: mindfulness as a useful treatment modality. Journal of Developmental and Behavioral Pediatrics, 40(6), 425-431. https://doi. org/10.1097/DBP.0000000000000682

Schunk, D. H. (1991). Self-efficacy and academic motivation. Educational Psychologist, 26(3-4), 207-231. https://doi.org/10.1080/ 00461520.1991 .9653133

Singh, S., Roy, D., Sinha, K., Parveen, S., Sharma, G., \& Joshi, G. (2020). Impact of COVID-19 and lockdown on mental health of children and adolescents: a narrative review with recommendations. Psychiatry Research, 293, Article 113429. https://doi.org/10.1016/j.psychres.2020. 113429

van Steensel, F. J. A., \& Bögels, S. M. (2015). CBT for anxiety disorders in children with and without autism spectrum disorders. Journal of Consulting and Clinical Psychology, 83(3), 512-523. https://doi.org/10. 1037/a0039108 
Yogman, M., Garner, A., Hutchinson, J., Hirsh-Pasek, K., \& Golinkoff, R. M. (2018). The Power of play: a pediatric role in enhancing development in young children. Pediatrics, 142(3). https://doi.org/10.1542/peds. 2018-2058

Authors: Allison L. Taylor, B.S. (altaylor8@bsu.edu)

Andrew S. Davis, Ph.D. (davis@bsu.edu)

Address: 2000 W. University Ave., Teachers College 505, Muncie, IN 47306

Office Phone: 765-285-8500

Office Fax: 765-285-3653

Affiliation: Ball State University

\section{The Efficacy of SSRI on Pediatric Panic Disorder and CBT}

\section{Objectives}

Anxiety disorders, including panic disorder, have the potential to present with significant disruptive neurocognitive concerns and thus should be an important avenue of neuropsychological research. Two of the most common interventions for pediatric panic disorder include cognitive behavioral therapy (CBT) and selective serotonin reuptake inhibitors (SSRI). Despite the effectiveness of these interventions, few studies have examined the effects on children when these are combined. This poster will review the existing literature on the efficacy of a combined treatment of CBT and SSRI on children with panic disorder.

\section{Data Selection}

Literature was obtained through searches in the following databases: PsycINFO, PsycARTICLES, ERIC, and MEDLINE with Full Text. The searches used a combination of the following terms: 'panic attack' or 'panic disorder,' with 'child,' 'children,' 'adolescent,' 'teenager,' 'youth,' 'pediatric,' or 'juvenile,' with 'cognitive behavioral therapy' or 'CBT,' with 'SSRI' or 'selective serotonin reuptake inhibitors.' After the searches, a total of 24 articles were found with only 9 relevant and somewhat related to pediatric neuropsychology.

\section{Data Analysis}

The 9 relevant articles were reviewed and synthesized. The removal of the terms 'child,' 'children,' 'adolescent,' 'teenager,' 'youth,' 'pediatric,' or 'juvenile' resulted in 178 articles. From this search, 4 additional articles were retained.

\section{Conclusions}

Pediatric panic disorder and its interventions have been widely studied, but there appears to be a lack of information that addresses the efficacy of both SSRI and CBT as a combined treatment in children. Given that SSRIs have potentially significant side effects, this would seem to be an oversight. A combined therapy of SSRIs and CBT is shown to be more effective than CBT alone. After reviewing the current findings, it is evident that more research needs to be conducted in this area. The implications for researchers and practitioners will also be discussed.

\section{Neuropsychology Practice and Assessment in a COVID-19 World}

Authors: April M. Taylor, M.A. (ammullen@bsu.edu), Adrianna M. Caballero, M.A. (amcaballero@bsu.edu)

Address: 2000 W. University Ave., Teachers College 505, Muncie, IN 47306

Office Phone: 765-285-8500

Office Fax: 765-285-3653

Affiliation: Ball State University

Objectives: When the COVID-19 pandemic hit, neuropsychology practitioners and trainees were forced to immediately switch to remote provision of services (Marra et al., 2020). Although telehealth and telepsychology services were offered as early as the 1980s (Salinas et al., 2020), few neuropsychology practitioners utilized this method. The pandemic offered a unique opportunity to explore telehealth as a means to reach patients. By the end of 2020 , multiple institutions had published articles outlining their transition process and how neuropsychological assessment and treatment was modified to fit a "new normal." The purpose of this review is to compile the recommendations for, considerations about, and benefits of remote neuropsychology.

Data Selection: Literature was obtained via searches of peer-reviewed journals available in the following databases: Academic Search Premier, PsycInfo, PsycArticles, ERIC, EBSCO, and MEDLINE. The following search terms were used: "covid-19" or "coronavirus" or "2019-ncov" or "sars-cov-2" or "cov-19" and "neuropsychology" or "neuropsychological" and "telehealth" or "telemedicine" or "telepsychology" or "teleneuropsychology" or "online" or "contactless" or "social distancing." Journals were included if they were scholarly and peer-reviewed. A total of 128 articles were found with 34 articles being retained for relevancy.

Data Analysis: All 34 articles were reviewed and synthesized.

Conclusions: Three themes emerged from the literature: guidelines for practice, concerns and considerations, and benefits of remote services. Although there is no formal guideline for virtual or remote neuropsychological assessment and treatment, many institutions offered suggestions based on what worked and what did not work for them. Others offered considerations for moving to remote practice (e.g., virtual confidentiality, documenting changes to standardization; Bilder et al., 2020) and silver linings (e.g., reaching underserved populations; Caze et al., 2020). This review will provide a synthesis of the available literature on remote neuropsychological practice and assessment and explore future directions for the field in a virtual format.

Title: Credible vs. Non-credible PVT on T.O.V.A in ADHD Youth: Replication

Authors: Hardian Thamrin, M.A., ${ }^{1}$ Maraen B. Foley, B.S., ${ }^{2}$ Sarah J. Shipley, ${ }^{3}$ and Christopher J. Nicholls, Ph.D. ${ }^{4}$

${ }^{1}$ Email: student@thenichollsgroup.com

Mailing address: 9965 N. 95 St. Ste. 101, Scottsdale, AZ 85258

Phone number: (480) 998-2303

Fax number: (480) 998-3169

Affiliation: The Nicholls Group, Scottsdale, AZ; Arizona State University, Tempe

${ }^{2}$ Email: mf@thenichollsgroup.com

Mailing address: 9965 N. 95 St. Ste. 101, Scottsdale, AZ 85258

Phone number: (480) 998-2303

Fax number: (480) 998-3169

Affiliation: The Nicholls Group, Scottsdale, AZ

${ }^{3}$ Email: sjshipl1@asu.edu

Mailing address: 9965 N. 95 St. Ste. 101, Scottsdale, AZ 85258

Phone number: (480) 998-2303

Fax number: (480) 998-3169

Affiliation: The Nicholls Group, Scottsdale, AZ; Arizona State University, Tempe

${ }^{4}$ Email: cn@thenichollsgroup.com

Mailing address: 9965 N. 95 St. Ste. 101, Scottsdale, AZ 85258

Phone number: (480) 998-2303

Fax number: (480) 998-3169

Affiliation: The Nicholls Group, Scottsdale, AZ; Arizona State University, Tempe

\section{Abstract:}

Objectives: Performance validity testing (PVT) has been found to be important in the evaluation of children and adolescents who present with symptoms of ADHD. The Test of Variables of Attention (T.O.V.A) has an embedded PVT measure for adults, but not children. Our previous research on 50 youth with $\mathrm{ADHD}^{1}$ showed that the Omission Error could

\footnotetext{
${ }^{1}$ Nicholls, C.J., Winstone, L.K., DiVirgilio, \& Foley, M.F. (2020) Test of Variables of Attention performance among ADHD children with credible vs. non-credible PVT performance. Applied Neuropsychology: Child Vol. 9, No. 2
} 
potentially function as an embedded measure of effort within the TOVA performance of children, but was limited by a relatively small sample size. This study aimed to replicate the previous findings by comparing the TOVA performance of a larger sample of individuals.

Methods: 146 youth $(69 \%$ male; mean age $=12.77, \mathrm{SD}=2.49$, age range 8-16) were selected from archival data of children referred for and subsequently diagnosed with ADHD, based on DSM- 5 criteria. T-tests compared the between-group difference of those who had evidence of PVT (Green's Word Memory Test, Medical Symptom Validity Test, or Nonverbal Medical Symptom Validity Test) failure $(N=20)$ and those who passed $(N=126)$ on TOVA performance variables standard scores. Results: Those who failed PVT were found to make significantly more Total Omission Errors $(t=-2.30, p=.032$, Cohen's $d=-1.09)$ than those who passed PVT measures. In addition, there was a trend for who those failed PVTs to have lower Response Time Variability $(t=-2.05, p=$ $.053, d=-.71)$ and higher Total Commission Errors $(t=-1.85, p=.080$, $d=-1.49$ )

Conclusion: Total Omission Errors remained to be a consistent predictor of poor effort. Thus, significantly greater than average omission errors should be interpreted with caution.

\section{Neuropsychological Monitoring Following Newborn Screening (NBS) for X-Linked Adrenoleukodystrophy (X-ALD)}

\author{
Ashley M. Whitaker, PhD, ABPP-CN \\ Cancer and Blood Disease Institute \\ Children's Hospital Los Angeles \\ 4650 Sunset Blvd, MS \#54 \\ Los Angeles, CA 90027 \\ p: 323-361-2744 | f: 323-361-7128 | e: awhitaker@chla.usc.edu
}

Objective: The purpose of this theoretical paper is to highlight the importance of neuropsychological evaluation for early detection of disease progression in X-linked adrenoleukodystrophy (X-ALD) following positive newborn screening (NBS).
Discussion: X-ALD NBS was included in the recommended uniform

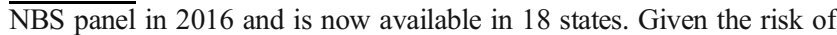
developing the fatal (if untreated) childhood cerebral phenotype (CCALD) and need for quick intervention with hematopoietic stem cell transplant (HCST) upon CCALD symptom onset to halt disease progression, monitoring of children identified as positive for X-ALD is critical. Several surveillance models have been proposed to examine adrenal function and brain magnetic resonance imaging (MRI) annually from birth/ age 1 to age 3-4 (when risk of CCALD onset increases), followed by every six months until age 10-12 (when CCALD phenotype risk decreases), and then annually afterwards (Benjelloun et al., 2017; Eng \& Regelmann, 2020; Kemper et al., 2017; Vogel et al., 2015).

Neuropsychological results can predict early CCALD disease progression (Riva et al., 2000) and post-HCST outcomes (Peters et al., 2004; Pierpont et al., 2018), even before changes on MRI (Kaga et al., 2009). Several authors recommend neuropsychology referral/surveillance for asymptomatic children with X-ALD (Miller et al., 2011; Polgreen et al., 2011; Shimozawa et al., 2011; Tran et al., 2017). However, neuropsychological monitoring has not been included in X-ALD surveillance models. Instead, many medical centers rely primarily on imaging and associated Loes scores to determine disease progression and inform treatment planning.

Conclusion: Neuropsychological changes are sensitive to early CCALD symptom onset, can predict post-HCST prognosis, and may even precede Loes score increases, especially in rapidly progressing cases. It is important for neuropsychologists to advocate for integration of neuropsychological evaluation into standard monitoring protocols following identification of X-ALD on NBS to help identify CCALD onset and guide intervention.

Publisher's Note Springer Nature remains neutral with regard to jurisdictional claims in published maps and institutional affiliations. 